\title{
Microwave-assisted Synthesis of Hybrid Heterocycles as Potential Anticancer Agents
}

\author{
Avula Srinivas,* Malladi Sunitha, Kammachichu Raju, Banothu Ravinder, \\ Siluveru Anusha, Thallapalli Rajasri, Pothuganti Swapna, Dupa Sushmitha, \\ Deva Swaroopa, Gurala Nikitha and Chakunta Govind Rao
}

\author{
Department of Chemistry, Vaagdevi Degree \& PG College \\ Kishanpura, Warangal, Telangana, India 506001 \\ *Corresponding author: E-mail: avula.sathwikreddy@gmail.com
}

Received: 24-12-2016

\begin{abstract}
In a one pot procedure, a series of novel hybrid heterocycles $\mathbf{6 a}-\mathbf{g}$ and $7 \mathbf{a}-\mathbf{g}$ were prepared by condensation of (3aS,4S,6S,6aS)-6-((1-(4-chlorophenyl)-1H-1,2,3-triazol-4-yl)methoxy)-2,2-dimethyltetrahydrofuro[3,4- $d][1,3]$ dioxole-4-carbaldehyde 5 with mercapto acids and primary amines in the presence of $\mathrm{ZnCl}_{2}$ under both microwave irradiation and conventional heating conditions. Compound $\mathbf{5}$ was prepared from di-acetone D-mannose via a click reaction, primary acetonide deprotection and oxidative cleavage. Characterization of new compounds has been done by IR, NMR, MS and elemental analysis. Anticancer activity of the compounds has also been evaluated.
\end{abstract}

Keywords: D-mannose, click reaction, cyclisation, anticancer activity

\section{Introduction}

1,2,3-Triazoles are one of the most important classes of heterocyclic organic compounds, which are reported to be present in a plethora of biologically active compounds, useful for diverse therapeutic areas. ${ }^{1}$ The 1,2,3-triazole motif is associated with diverse pharmacological activities, such as antibacterial, antifungal, hypoglycemic, antihypertensive and analgesic properties. Polysubstituted five-membered aza heterocycles rank as the most potent glycosidase inhibitors. ${ }^{2}$ Further, this nucleus in combination with or in linking with various other classes of compounds such as amino acids, steroids, aromatic compounds, carbohydrates etc., became prominent in having various pharmacological properties. ${ }^{3}$ 1,2,3-Triazole modified carbohydrates have became easily available after the discovery of the $\mathrm{Cu}(\mathrm{I})$-catalyzed azide-alkynes 1,3-dipolar cycloaddition reaction ${ }^{4}$ and quickly became a prominent class of non-natural sugar derivatives. The chemistry and biology of triazole modified sugars is dominated by triazole glycosides. ${ }^{5}$ Therefore, the synthesis and investigation of biological activity of 1,2,3-triazole glycosides is an important objective, which also received a considerable attention by the medicinal chemists.
Thiazolidinones and 1,2,3-triazoles represent important classes of drugs in medicinal chemistry. They are among the most extensively investigated compounds by biochemists and medicinal chemists. ${ }^{6}$ Thiazolidinones in particular show interesting anticancer, ${ }^{7}$ anti-HIV, ${ }^{8}$ tuberculostatic, ${ }^{9}$ antihistaminic, ${ }^{10}$ anticonvulsant, ${ }^{11}$ antibacterial, ${ }^{12}$ and anti arrhythmic ${ }^{13}$ activities.

So called hybrid molecules have been shown to be highly active and effective in medicinal chemistry. Synergistic effects are obtained via hybridization of two different bioactive moieties with complementary pharmacophoric functions, or with different modes of action. ${ }^{14}$ The confirmation of this hypothesis has been well established in previous studies of 4-thiazolidinones coupled with other heterocyclic fragments, ${ }^{15}$ i.e. resulting in high anti tumor activity.

Microwave irradiation is an alternative heating technique based on the transformation of electromagnetic energy into heat. Often this method increases the rate of chemical reactions ${ }^{16}$ and results in higher yields. In recent years, multi component reactions (MCRs) ${ }^{17}$ have received interesting attention due to their simplicity, efficiency, atom economy, shortened reaction times, and the possibility for diversity oriented synthesis. 
Following the successful introduction of triazoles and thiazolidinones, microwave-assisted MCR reactions, inspired by the biological profile of triazoles, thiazolidinones, and in the continuation of our work on biologically active heterocycles ${ }^{18-29}$ we have developed a series of novel triazole-linked thiazolidenone derivatives, we have investigated the application of microwave irradiation for the synthesis of our hybrid molecules and evaluated their anticancer activity.

\section{Result and Discussion}

Di-acetone D-mannose (1), prepared from D-(+)mannose by treating with acetone in the presence of a catalytic amount of sulphuric acid according to the literature procedure ${ }^{30}$ on subsequent propargylation in DMF in the presence of $\mathrm{NaH}$ in $1 \mathrm{~h}$ afforded propargyl ether $\mathbf{2}(80 \%)$. Next, the propargyl ether was converted into triazole $\mathbf{3}$<smiles>CC1(C)O[C@@H]2[C@@H](O)O[C@H]([C@H]3COC(C)(C)O3)[C@@H]2O1</smiles>

1
4
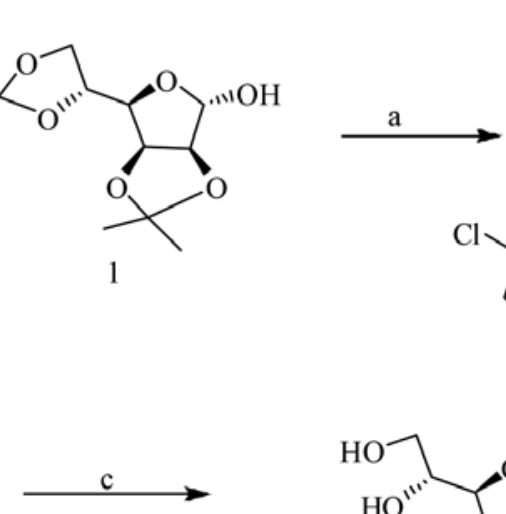<smiles>CC1(C)OCCO1</smiles><smiles>Cl[Mg]Cl</smiles><smiles>Clc1ccccc1</smiles><smiles>C/C=C/CN/C=C\CO[C@H]1O[C@H]([C@H](O)CO)[C@H]2OC(C)(C)O[C@H]12</smiles>

4

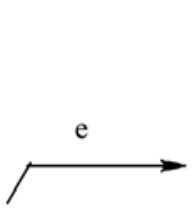

$\mathrm{R}-\mathrm{NH}_{2}$

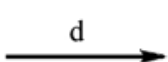<smiles>[R]NC[C@H]1O[C@H](OCc2cn(-c3ccc(Cl)cc3)nn2)[C@H](OC(C)(C)C)[C@@H]1OC=O</smiles>

5
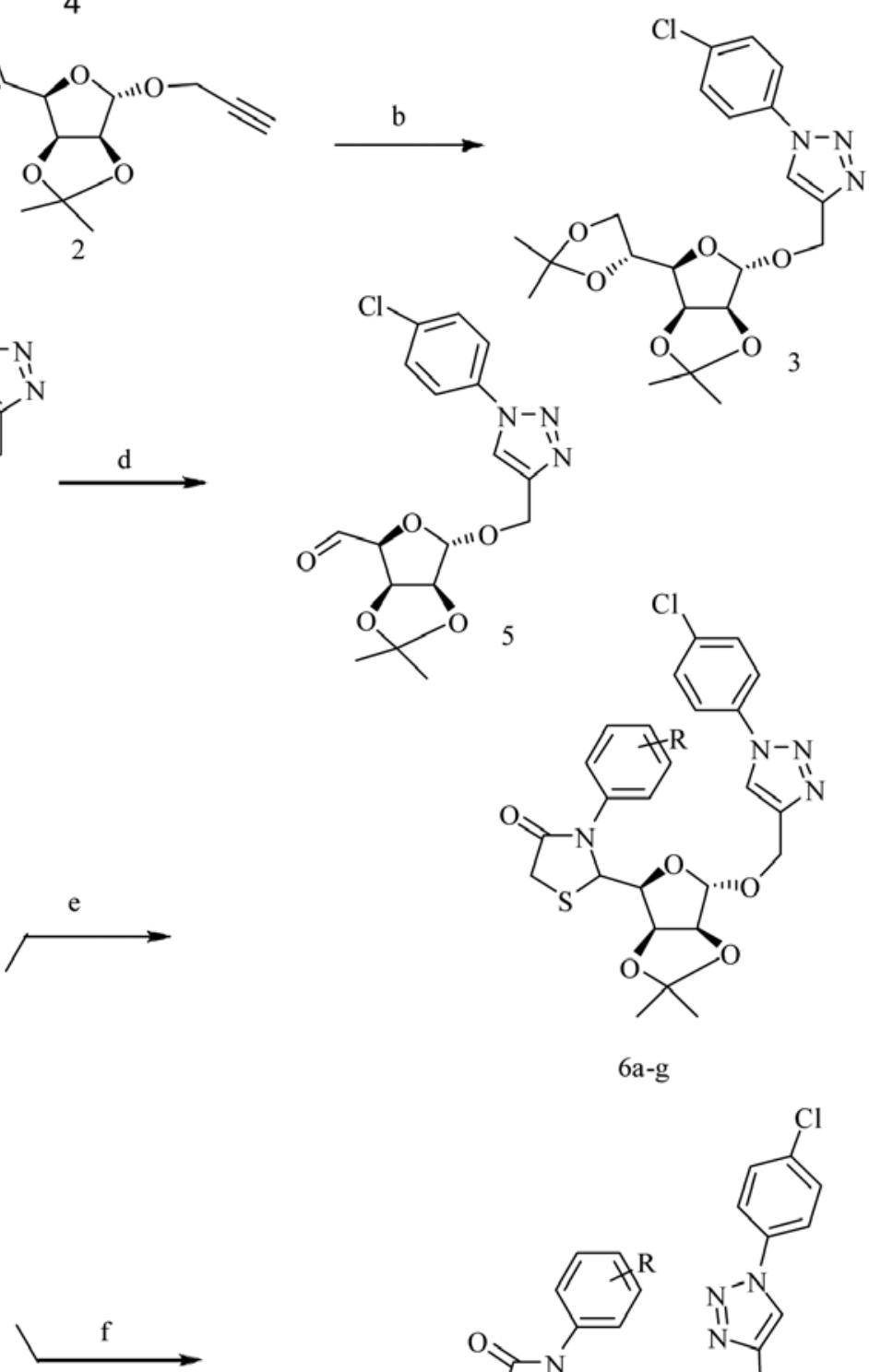

$6 \mathrm{a}-\mathrm{g}$<smiles>[R]Cc1ccc(N2C(=O)C(CC(=O)O)SC2[C@@H]2O[C@H](OCc3cn(-c4ccc(Cl)cc4)nn3)[C@H]3OC(C)(C)O[C@@H]32)cc1</smiles>

$7 \mathrm{a}-\mathrm{g}$

Sheme 2. Reagents and conditions: (a) Propargyl bromide, $\mathrm{NaH}, \mathrm{DMF}, 0{ }^{\circ} \mathrm{C} \rightarrow \mathrm{rt}$; (b) p-Chlorophenyl azide, glucose, $\mathrm{CuSO}_{4} \cdot 5 \mathrm{H}_{2} \mathrm{O}, \mathrm{THF} / \mathrm{H}_{2} \mathrm{O}$; (c) $60 \% \mathrm{AcOH}$; (d) $\mathrm{NaIO}_{4}, \mathrm{CH}_{2} \mathrm{Cl}_{2}$; (e) $\mathrm{Ar}-\mathrm{NH}_{2}, \mathrm{SHCH}_{2} \mathrm{COOH}, \mathrm{ZnCl}_{2}$, toluene, $80{ }^{\circ} \mathrm{C}$, MW $110{ }^{\circ} \mathrm{C}$; (f) $\mathrm{Ar}-\mathrm{NH}_{2}$, thio malic acid, $\mathrm{ZnCl} 2$ toluene, $80{ }^{\circ} \mathrm{C}$, MW $110{ }^{\circ} \mathrm{C}$. 
Table 1. Synthesis of compounds $6 \mathbf{a}-\mathbf{g}$ and $7 \mathbf{a}-\mathbf{g}$

\begin{tabular}{|c|c|c|c|c|c|c|}
\hline \multirow{2}{*}{ Compound } & \multirow{2}{*}{$\mathbf{R}$} & \multirow{2}{*}{ Mol. formula } & \multicolumn{2}{|c|}{ Reaction time } & \multicolumn{2}{|c|}{ Yield } \\
\hline & & & $\mathbf{A}(\mathbf{h})$ & B (min) & $\mathbf{A}$ & B \\
\hline $6 \mathbf{6 a}$ & $\mathrm{C}_{6} \mathrm{H}_{5}$ & $\mathrm{C}_{25} \mathrm{H}_{25} \mathrm{ClN}_{4} \mathrm{O}_{5} \mathrm{~S}$ & 3.5 & 5 & 62 & 80 \\
\hline $6 \mathbf{b}$ & $4-\mathrm{Cl}-\mathrm{C}_{6} \mathrm{H}_{4}$ & $\mathrm{C}_{25} \mathrm{H}_{24} \mathrm{Cl}_{2} \mathrm{~N}_{4} \mathrm{O}_{5} \mathrm{~S}$ & 2.5 & 6 & 75 & 89 \\
\hline $6 c$ & $4-\mathrm{NO}_{2}-\mathrm{C}_{6} \mathrm{H}_{4}$ & $\mathrm{C}_{25} \mathrm{H}_{24} \mathrm{ClN}_{5} \mathrm{O}_{7} \mathrm{~S}$ & 3.0 & 6 & 65 & 82 \\
\hline 6d & $2-\mathrm{CH}_{3}-\mathrm{C}_{6} \mathrm{H}_{4}^{4}$ & $\mathrm{C}_{26} \mathrm{H}_{27} \mathrm{ClN}_{4} \mathrm{O}_{5} \mathrm{~S}$ & 2.0 & 5 & 65 & 86 \\
\hline $6 e$ & $4-\mathrm{CH}_{3}-\mathrm{C}_{6} \mathrm{H}_{4}$ & $\mathrm{C}_{26} \mathrm{H}_{27} \mathrm{ClN}_{4} \mathrm{O}_{5} \mathrm{~S}$ & 2.5 & 5 & 69 & 88 \\
\hline $6 f$ & $3-\mathrm{OH}-\mathrm{C}_{6} \mathrm{H}_{4}$ & $\mathrm{C}_{25} \mathrm{H}_{25} \mathrm{ClN}_{4} \mathrm{O}_{6} \mathrm{~S}$ & 3.0 & 5 & 74 & 86 \\
\hline $6 \mathrm{~g}$ & $4-\mathrm{OH}-\mathrm{C}_{6} \mathrm{H}_{4}$ & $\mathrm{C}_{25} \mathrm{H}_{25} \mathrm{ClN}_{4} \mathrm{O}_{6} \mathrm{~S}$ & 2.0 & 3 & 82 & 91 \\
\hline $7 \mathbf{a}$ & $\mathrm{C}_{6} \mathrm{H}_{5}$ & $\mathrm{C}_{27} \mathrm{H}_{27} \mathrm{ClN}_{4} \mathrm{O}_{7} \mathrm{~S}$ & 3.5 & 5 & 61 & 79 \\
\hline $7 b$ & $4-\mathrm{Cl}-\mathrm{C}_{6} \mathrm{H}_{4}$ & $\mathrm{C}_{27} \mathrm{H}_{26} \mathrm{Cl}_{2} \mathrm{~N}_{4} \mathrm{O}_{7} \mathrm{~S}$ & 2.5 & 6 & 68 & 82 \\
\hline $7 c$ & $4-\mathrm{NO}_{2}-\mathrm{C}_{6} \mathrm{H}_{4}$ & $\mathrm{C}_{27} \mathrm{H}_{26} \mathrm{Cl}_{2} \mathrm{~N}_{5} \mathrm{O}_{9} \mathrm{~S}$ & 3.0 & 7 & 60 & 79 \\
\hline $7 d$ & $2-\mathrm{CH}_{3}-\mathrm{C}_{6} \mathrm{H}_{4}$ & $\mathrm{C}_{28} \mathrm{H}_{29} \mathrm{ClN}_{4} \mathrm{O}_{7} \mathrm{~S}$ & 2.5 & 5 & 72 & 81 \\
\hline $7 e$ & $4-\mathrm{CH}_{3}-\mathrm{C}_{6} \mathrm{H}_{4}$ & $\mathrm{C}_{28} \mathrm{H}_{29} \mathrm{ClN}_{4} \mathrm{O}_{7} \mathrm{~S}$ & 2.0 & 5 & 64 & 82 \\
\hline $7 f$ & $3-\mathrm{OH}-\mathrm{C}_{6} \mathrm{H}_{4}$ & $\mathrm{C}_{27} \mathrm{H}_{27} \mathrm{ClN}_{4} \mathrm{O}_{8} \mathrm{~S}$ & 3.0 & 5 & 79 & 87 \\
\hline $7 \mathrm{~g}$ & $4-\mathrm{OH}-\mathrm{C}_{6} \mathrm{H}_{4}^{4}$ & $\mathrm{C}_{27} \mathrm{H}_{27} \mathrm{ClN}_{4} \mathrm{O}_{8} \mathrm{~S}$ & 2.5 & 4 & 69 & 90 \\
\hline
\end{tabular}

A: conventional heating; B: microwave irradiation.

(82\%) by using a 1,3-dipolar cycloaddition with $p$-chlorophenyl azide, which was carried out at ambient temperature in the presence of $\mathrm{CuSO}_{4}$ and glucose which reduced $\mathrm{CuSO}_{4}$ in a mixture of $1: 1 t-\mathrm{BuOH}-\mathrm{H}_{2} \mathrm{O}$. Acid hydrolysis of 5,6-acetonide 3 in $60 \% \mathrm{AcOH}$ furnished the diol $4(85 \%)$, which on oxidative cleavage with $\mathrm{NaIO}_{4}$ gave the aldehyde 5 (Scheme 1). Subsequently one pot synthesis of triazole-linked thiazolidinone glycosides was carried out by the condensation reaction between $\mathbf{5}$, primary aromatic amine and a thioglycolic acid and thiomalic acid in the presence of $\mathrm{ZnCl}_{2}$ under microwave irradiation or conventional heating (Scheme 2). In the classic method, the reactions were performed in dry toluene at reflux for a long time (2-4 h), often leading to degradation processes and consequent low yields of isolated products, whereas upon the application of microwave-assisted technology the reaction was completed in only 5-10 minutes and the compounds, isolated by conventional work-up, were obtained in satisfactory yields, often higher than those achieved by traditional methods (Table 1). The structures of synthesized compounds were confirmed by IR, NMR, MS and elemental analysis. Further, the compounds were subject to anticancer testing.

\section{Cytotoxicity Evaluation Against Different Cancer Cell Lines}

The cytotoxic effect of the compounds was tested by performing a Sulforhodamine B Assay (SRB) on different representative cell lines. Initially, the cell line of interest was seeded in a flat bottom 96-well plate (5000 cells/100 $\mu \mathrm{L}$ ) in a medium containing $10 \%$ serum, followed by incubation for 18-20 $\mathrm{h}$ in an incubator continuously supplied with $5 \% \mathrm{CO}_{2}$, so as to ensure proper adherence of the cells to the surface bottom of the wells. After $18 \mathrm{~h}$ the cells were treated with the compound. Working dilutions of concentration of the compounds were prepared, of which $2 \mu \mathrm{L}$ aliquot was added to each well, thereby making the final concentration of compound 0 to $100 \mu \mathrm{M}$. Each compound was tested in triplicate and the cytotoxicity was determined as the average of that triplicate. DMSO and doxorubicin (as standard control anti cancer drug) were taken as vehicle and positive controls, respectively. Further, the plates were incubated for another $48 \mathrm{~h}$ in an incubator maintained at $37{ }^{\circ} \mathrm{C}$ with a constant supply of $5 \% \mathrm{CO}_{2}$. After the period of $48 \mathrm{~h}$, the cells were fixed using $10 \%$ TCA solution and incubated for $1 \mathrm{~h}$ at $4{ }^{\circ} \mathrm{C}$ after which the plate was rinsed carefully with MQ water and air dried; this was followed by addition of $0.057 \%$ SRB solution which was kept for approx. $30 \mathrm{~min}$ before it was rinsed off using $1 \%$ acetic acid. The plates were then air dried and the absorbance was measured using Perkin-Elmer Multimode Reader at $510 \mathrm{~nm}$. To measure the absorbance, $100 \mu \mathrm{L}$ of $10 \mathrm{mM}$ Tris Base was added to each well to solubilize the SRB. The value of absorbance is directly proportional to cell growth and is thus used to calculate the $\mathrm{IC}_{50}$ values. In this study for initial screening, four types of cancer cell lines, i.e. human lung cancer (A549), human breast cancer (MCF-7), prostate cancer (DU145) and HeLa cell lines were tested for the cytotoxic effect of the series of compounds. Based on the $\mathrm{IC}_{50}$ values obtained, the compound $\mathbf{7 b}$ was picked for further assays to ascertain its effect on prostrate cancer cell line (DU145).

\section{1. Change in Morphology}

Based on the cytotoxic ability of the compound, its effect on the morphology of the cells was also ascertained. To achieve this, a 24-well plate was seeded with cells in a manner previously described and incubated for $18-20 \mathrm{~h}$. Then, the cells were treated with increasing concentra- 
tions of $\mathbf{7 b}$. After another $48 \mathrm{~h}$ of incubation, the experiment was terminated and the cells were observed under the microscope and images were captured using Olympus Xi71 microscope.

\section{2. Colony Formation Assay}

The long term effect of the $\mathbf{7 b}$ on the anchorage independent nature of cancer cells was further tested in the following experiment. The experiment was a soft agar assay which was conducted as reported previously with minor modifications. In the experiment, base agar was prepared by mixing $1 \%$ of agarose (Bacto Agar: Becton, Dickinson, Sparks, MD) with $2 \times$ DMEM along with $20 \%$ FBS and $2 \mathrm{X}$ antibiotics in 6-well plates in order to achieve final concentration of $0.5 \%$ of agar in $1 \mathrm{X}$ growth medium with $10 \%$ serum concentration. After the solidification of the base agar, $2.5 \times 10^{4}$ cells were mixed with cultivation medium containing compound at varying concentrations along with agar solution to obtain a final concentration of $0.35 \%$ agar. This was spread on top of the base agar previously solidified. The plate was incubated for 9 days with periodic replenishment every 3 days with medium and compound. Over the period of time, plates were monitored regularly for appearance of colonies. After 9 days of incubation the plates were stained with $0.005 \%$ crystal violet solution until colonies turned purple in color. The excessive stain was washed off using MQ water and the colonies were photographed and counted using a microscope.

\section{3. Determination of Caspase-3 and Caspase-9 Activities}

Caspase activity, specifically, caspase- 9 and caspase-3 activities were analyzed in the cell lysates obtained from DU 145 cells previously treated with compound $\mathbf{7 b}$. The activity was observed using fluorogenic substrates, namely Ac-DEVD-AMC and Ac-LEHD-AFC for caspase-3 and caspase-9, respectively. After $48 \mathrm{~h}$ treatment of cells with compound $\mathbf{7 b}$, harvested cells were lysed directly in caspase lyses buffer (50 mM HEPES, $5 \mathrm{mM}$ CHAPS, 5 mM DTT, pH 7.5). The lysates were incubated with the respective substrate (Ac-DEVD-AFC/Ac-LEHDAMC) in $20 \mathrm{mM}$ HEPES (pH 7.5), 0.1\% CHAPS, $2 \mathrm{mM}$ EDTA and $5 \mathrm{mM}$ DTT at $37{ }^{\circ} \mathrm{C}$ for $2 \mathrm{~h}$. The release of $\mathrm{AFC}$ and $\mathrm{AMC}$ was analyzed by a fluorimeter using an excitation/emission wavelength of 400/505 nm (for AFC) and 380/460 nm (for AMC) which is directly proportional to caspase- 9 and caspase- 3 activity, respectively. The observed fluorescence values were normalized with total protein concentration estimated by Bradford method and the relative caspase activities were calculated as the ratio of values between mock treated (DMSO) and treated cells.

\section{4. Senescence Assay}

Compounds with anti-cancer potential may have the possibility to induce senescence in cells, thus limiting their proliferation. The ability to induce cellular senescence was determined by measuring senescence-associated beta-galactosidase (SA- $\beta$ gal) activity (pH 6.0) in DU145 cells exposed to compound $\mathbf{7 b}$. A 24-well plate was seeded with DU 145 cells as previously described and treated with the compound and subsequently incubated for $48 \mathrm{~h}$. After $48 \mathrm{~h}$, the media was aspirated and the cells were washed with PBS $(2 \times 1 \mathrm{~min})$ and fixed by adding enough volume of fixation solution (2\% formaldehyde and $0.2 \%$ glutaraldehyde in PBS solution) to submerge the cells in solution. After incubation for $5 \mathrm{~min}$ at room temperature

Table 2. Four representative cell lines were tested with the series of compounds to determine their cytotoxicity. Table shows the $\mathrm{IC}_{50}$ values of the compounds against the cell lines.

\begin{tabular}{|c|c|c|c|c|c|c|c|c|c|}
\hline \multirow[b]{2}{*}{ S.No. } & \multirow{2}{*}{$\begin{array}{c}\text { Sample } \\
\text { codes }\end{array}$} & \multicolumn{2}{|c|}{ DU145 } & \multicolumn{2}{|c|}{ A549 } & \multicolumn{2}{|c|}{ HELA } & \multicolumn{2}{|c|}{ MCF 7} \\
\hline & & $\mathrm{IC}_{50}$ & Std. Dev & $\mathrm{IC}_{50}$ & Std. Dev & $\mathrm{IC}_{50}$ & Std. Dev & $\mathrm{IC}_{50}$ & Std. Dev \\
\hline 1 & $6 \mathbf{a}$ & 17.99 & 3.27 & 31.15 & 13.78 & $>100$ & - & 40.97 & 21.06 \\
\hline 2 & $6 b$ & 15.98 & 3.10 & 37.29 & 0.00 & $>100$ & - & 57.16 & 5.33 \\
\hline 3 & $6 c$ & 12.25 & 0.85 & 15.18 & 1.12 & 58.34 & 15.39 & 63.60 & 29.26 \\
\hline 4 & 6d & 37.71 & 18.26 & 33.64 & 6.64 & $>100$ & - & $>100$ & - \\
\hline 5 & $6 e$ & $>100$ & - & 29.81 & 0.62 & $>100$ & - & 66.30 & 8.84 \\
\hline 6 & $6 f$ & 16.91 & 2.37 & 21.84 & 4.68 & 67.07 & 42.33 & 18.73 & 2.11 \\
\hline 7 & $6 \mathrm{~g}$ & 8.76 & 0.68 & 10.70 & 1.11 & 24.29 & 1.02 & 19.51 & 0.48 \\
\hline 8 & $7 a$ & $>100$ & - & 43.67 & 6.33 & $>100$ & 19.62 & $>100$ & - \\
\hline 9 & $7 b$ & 8.76 & 0.68 & 10.7 & 1.11 & 24.29 & 1.02 & 19.5 & 0.48 \\
\hline 10 & $7 c$ & 23.87 & 1.06 & 49.98 & 7.33 & $>100$ & - & $>100$ & - \\
\hline 11 & 7d & $>100$ & - & 25.19 & 5.72 & $>100$ & - & $>100$ & - \\
\hline 12 & $7 e$ & 53.48 & 9.73 & 39.94 & 30.16 & 52.74 & 16.02 & 29.87 & 0.00 \\
\hline 13 & $7 f$ & 39.94 & 7.30 & 36.04 & 16.40 & 77.81 & 47.77 & 60.07 & 29.73 \\
\hline 14 & $7 g$ & 25.09 & 3.39 & 33.96 & 9.95 & 33.55 & 6.11 & 37.28 & 14.04 \\
\hline 15 & Doxorubicin & 6.70 & 0.10 & 8.49 & 0.13 & 10.89 & 0.09 & 8.62 & 1.52 \\
\hline
\end{tabular}


the fixation solution was removed and the cells were washed twice with PBS $(2 \times 1 \mathrm{~min})$. The resultant fixed cells were then stained with freshly prepared staining solution (40 $\mathrm{mM}$ citric acid/ $\mathrm{Na}$ phosphate buffer, $5 \mathrm{mM}$ $\mathrm{K}_{4}\left[\mathrm{Fe}(\mathrm{CN})_{6}\right] \cdot 3 \mathrm{H}_{2} \mathrm{O}, 5 \mathrm{mM} \mathrm{K}_{3}\left[\mathrm{Fe}(\mathrm{CN})_{6}\right], 150 \mathrm{mM}$ sodium chloride, $2 \mathrm{mM}$ magnesium chloride and $1 \mathrm{mg} \mathrm{X}$-gal in 1 $\mathrm{mL}$ distilled water) overnight at $37{ }^{\circ} \mathrm{C}$. The excess stain was removed by repeated washings with PBS and plate was allowed to dry at room temperature. The cells stained with SA- $\beta$ gal levels were observed and photographed under an Olympus Xi71 microscope.

\section{5. PI Uptake for Analysis of Cell Death}

Cell death induced by compound $\mathbf{7 b}$ was determined as a measure of PI uptake. Cells were harvested after treatment with compound at desired concentration and fixed in $70 \%$ ethanol at $-20{ }^{\circ} \mathrm{C}$ overnight. The cells were then collected in the form of pellet. All cells in the form of a pellet were then resuspended in PI solution (RNase $0.1 \mathrm{mg} / \mathrm{mL}$, Triton X-100 0.05\%, PI $50 \mu \mathrm{g} / \mathrm{mL}$ ) and incu- bated for $1 \mathrm{~h}$ in dark at room temperature. The excess PI solution was washed away by repeated washings with PBS buffer. The resultant PI uptake was analyzed by fluorescence activated cell sorting (FACS Caliber System; BD Bio-science, Erembodegem, Belgium) in a FL-2 fluorescence detector (10000 events were recorded

Table 3. Compound 7b induced G0/G1 phase cell cycle arrest in DU145 cells. Cells were treated with varying concentrations of compound $7 \mathbf{b}(5,10,15,20$ and $25 \mu \mathrm{M})$ for $48 \mathrm{~h}$ and cell cycle progression was examined by flow cytometry. Table shows the percentage cell fractions in G0/G1, S and G2/M phases of compound $7 \mathbf{b}$ treated DU145 cells.

\begin{tabular}{lccc}
\hline & G0/G1 & S & G2/M \\
\hline $\mathbf{D M S O}$ & 71.36 & 5.02 & 22.74 \\
$\mathbf{5} \boldsymbol{\mu M}$ & 63.92 & 8.10 & 22.16 \\
$\mathbf{1 0} \boldsymbol{\mu M}$ & 69.15 & 5.54 & 24.65 \\
$\mathbf{1 5} \boldsymbol{\mu M}$ & 71.86 & 3.92 & 22.51 \\
$\mathbf{2 0} \boldsymbol{\mu M}$ & 72.11 & 3.89 & 20.05 \\
$\mathbf{2 5} \boldsymbol{\mu M}$ & 76.48 & 2.99 & 18.77 \\
\hline
\end{tabular}
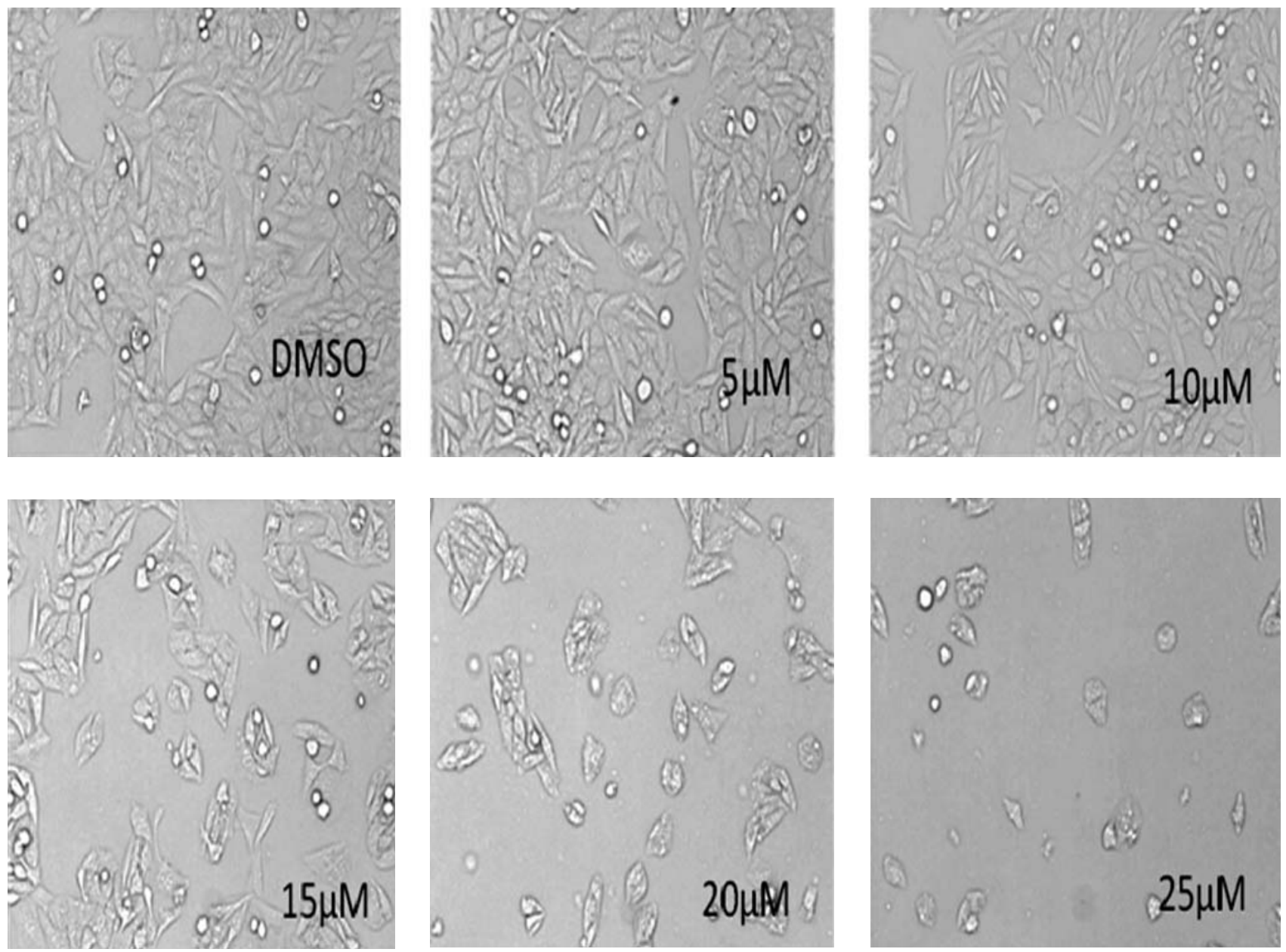

Figure 1. DU145 cell were treated with compound 7b at indicated concentration or DMSO. Upon exposure of DU145 cells to compound 7b the extent of change in cell morphology of cells is observed with increasing concentration. 

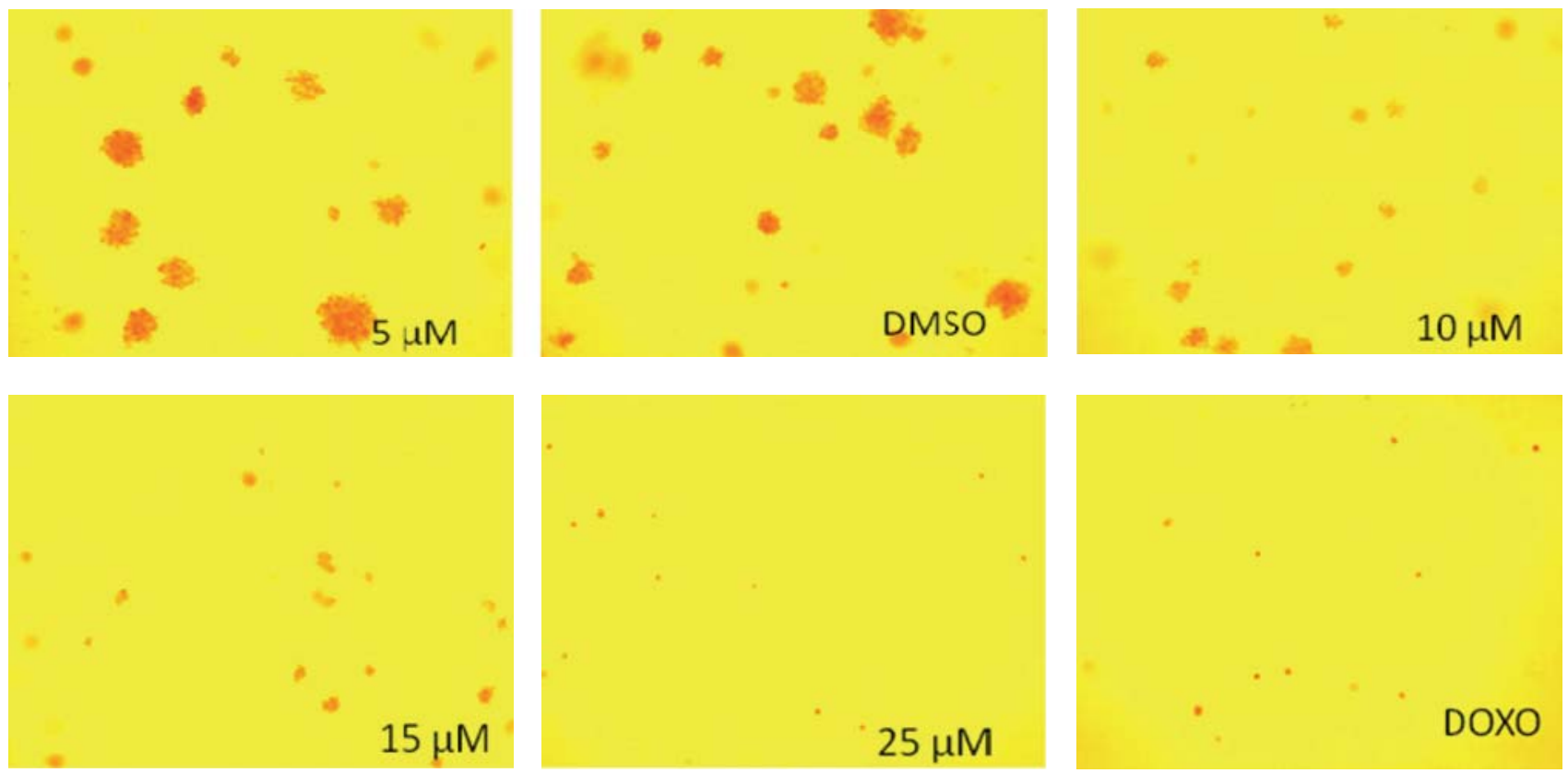

Figure 2. Long term effect of compound 7b on the number of colony-forming DU145 cells. DU145 cells were treated with desired concentration of $7 \mathbf{b}(0-25 \mu \mathrm{M})$ and allowed to grow for 9 days to form colonies. Representative images of the colony-forming assay are shown here. Number of colonies and their size formed by DU145 in soft agar is decreased on exposure to compound $\mathbf{7 b}$.
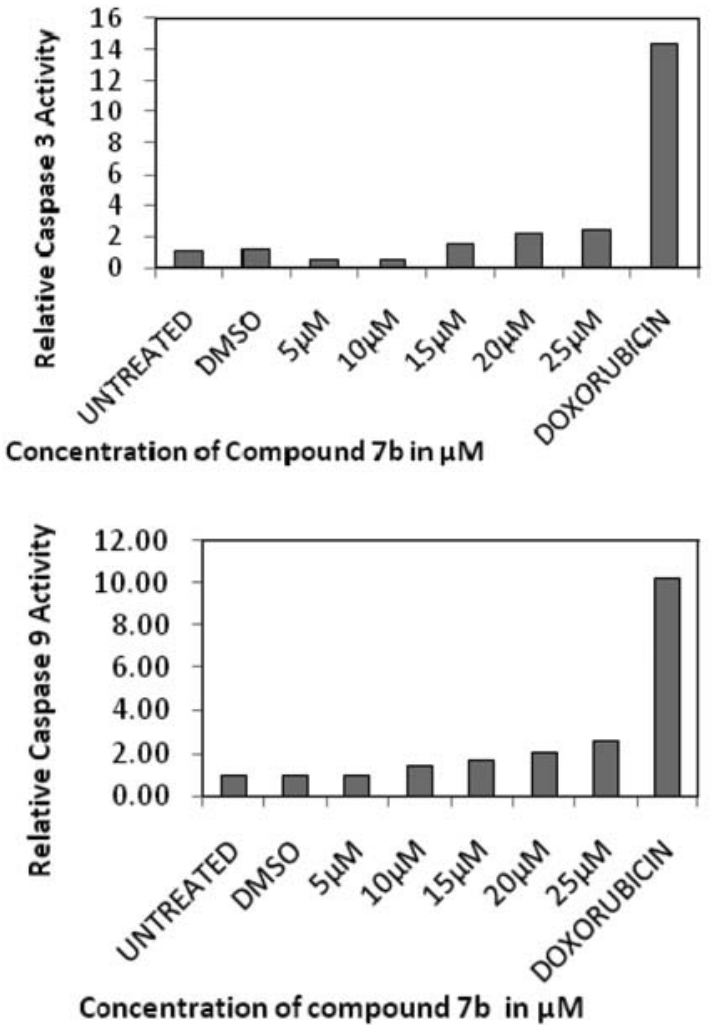

Figure 3. The ability of the compound to activate caspases in DU145 cells was observed. Treatment of DU145 cells with different concentration of $\mathbf{7 b}$ for $48 \mathrm{~h}$ induced activation of caspase- 3 (A) and caspase-9 (B) significantly in concentration dependent manner. Doxorubicin was used as control for activation of both caspases. All experiments were carried out in triplicates and mean values are presented here. for each condition). Flow cytometry data was analyzed using FCS express 4 software (De Novo Software, Los Angeles, CA).

\section{Experimental}

Commercial grade reagents were used as supplied. Solvents, except those of analytical grade, were dried and purified according to literature when necessary. Reaction progress and purity of the compounds were checked by thin-layer chromatography (TLC) on pre-coated silica gel F254 plates from Merck and compounds visualized either by exposure to UV light or dipping in $1 \%$ aqueous potassium permanganate solution. Silica gel chromatographic columns (60-120 mesh) were used for separations. Microwave reactions were carried out in mini lab microwave catalytic reactor (ZZKD, WBFY-201) and reaction mixture temperatures were measured through an immersed fibre-optic sensor. All melting points are uncorrected and measured using Fisher-Johns apparatus. IR spectra were recorded as $\mathrm{KBr}$ disks on a Perkin-Elmer FT IR spectrometer. The ${ }^{1} \mathrm{H}$ NMR and ${ }^{13} \mathrm{C}$ NMR spectra were recorded on a Varian Gemini spectrometer $(300 \mathrm{MHz}$ for ${ }^{1} \mathrm{H}$ and $75 \mathrm{MHz}$ for ${ }^{13} \mathrm{C}$ ). Chemical shifts are reported as $\delta$ ppm against TMS as internal reference and coupling constants $(J)$ are reported in $\mathrm{Hz}$ units. Mass spectra were recorded on a VG micro mass $7070 \mathrm{H}$ spectrometer. Elemental analyses $(\mathrm{C}, \mathrm{H}, \mathrm{N})$ determined by a Perkin-Elmer $240 \mathrm{CHN}$ elemental analyzer, were within $\pm 0.4 \%$ of theoretical. 

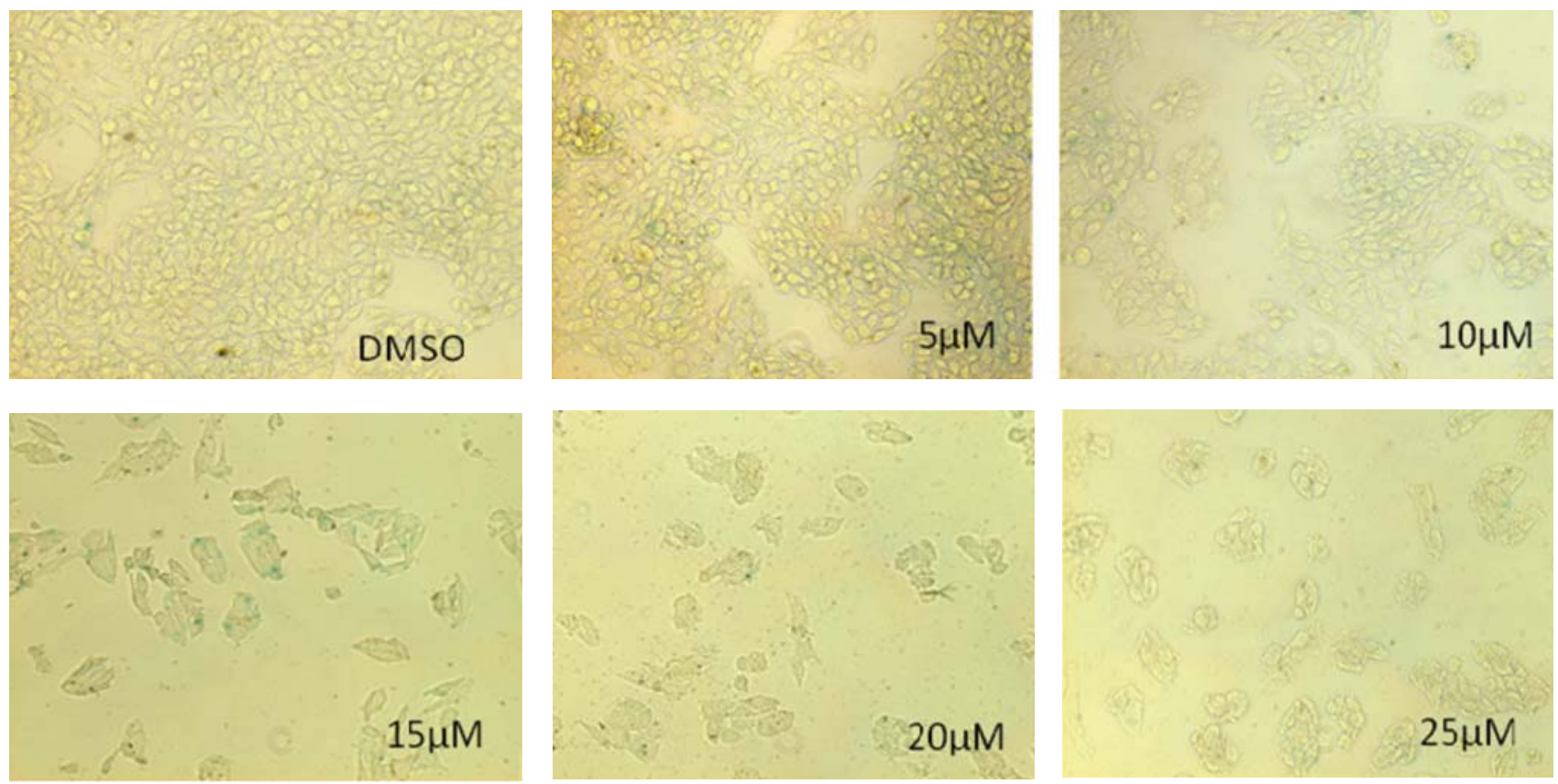

Figure 4. Senescence induced by compound $\mathbf{7 b}$ was quantified using SA- $\beta$ gal-staining. As shown in the figure, $7 \mathbf{b}$ did not induce senescence in cells as at higher concentrations the cells underwent apoptosis
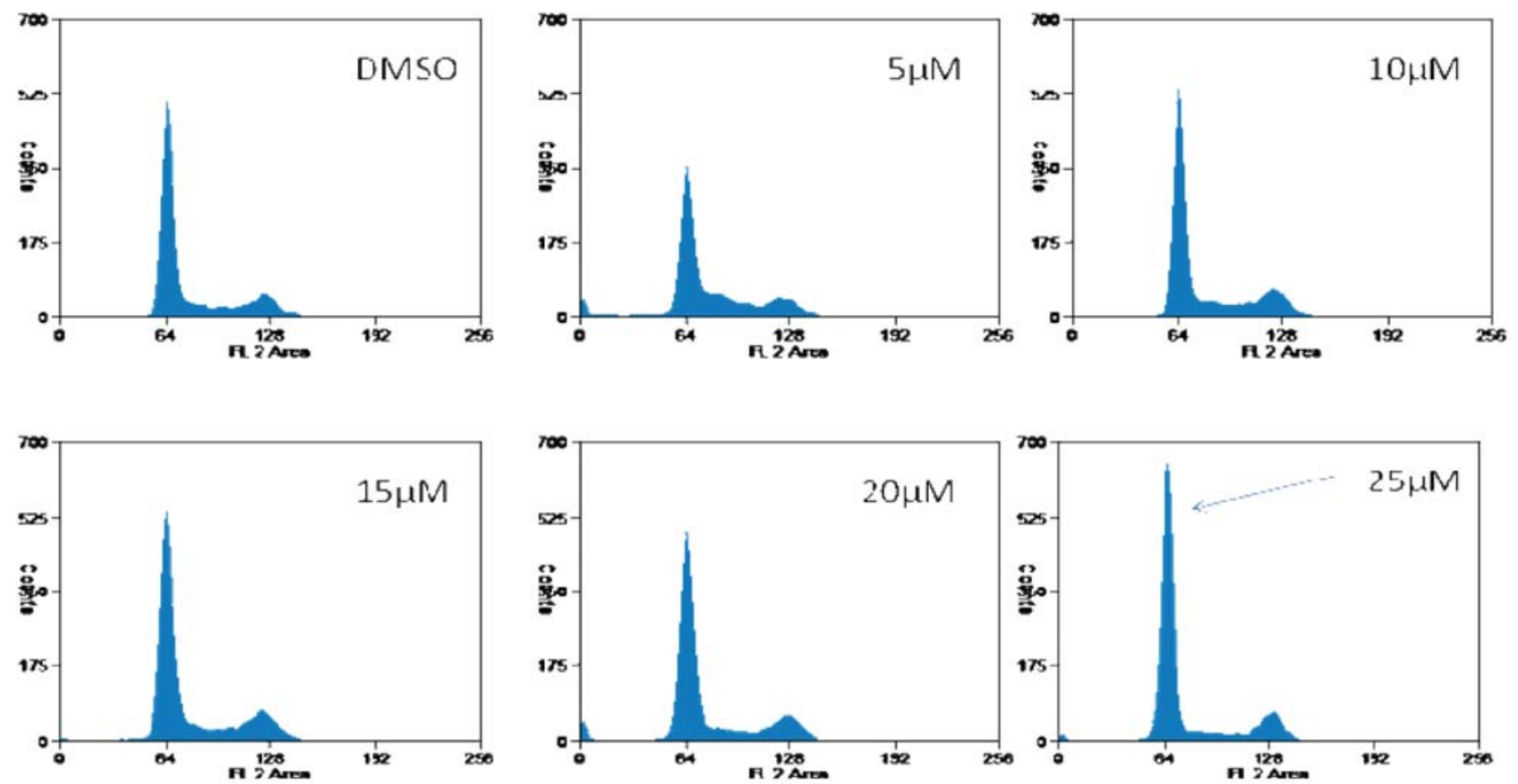

Figure 5. Cell cycle analysis of DU145 cells treated with compound 7b. Cells were treated with either DMSO or 7b and the DNA content was measured by propidium iodide staining to determine the distribution of cells in various phases of cell cycle. DMSO was taken as reference.

(3aS,4R,6S,6aS)-4-((R)-2,2-Dimethyl-1,3-dioxolan-4yl)-2,2-dimethyl-6-(prop-2-ynyloxy)tetrahydrofuro[3,4- $d][1,3]$ dioxole (2). Sodium hydride $(60 \%$ in mineral oil, $0.64 \mathrm{~g})$ was added to a stirred solution of $\mathbf{3}(3.6 \mathrm{~g}$, $13.84 \mathrm{mmol})$ in $\mathrm{DMF}(80 \mathrm{~mL})$ at $0{ }^{\circ} \mathrm{C}$ and allowed to stir for $30 \mathrm{~min}$. This yellow mixture was cooled to $0^{\circ} \mathrm{C}$ and treated with propargyl bromide $(4.2 \mathrm{~g})$ in DMF $(20 \mathrm{~mL})$. The dark brown reaction mixture was allowed to stir for an hour at room temperature and quenched (at 5-10 ${ }^{\circ} \mathrm{C}$ ) with saturated aqueous ammonium chloride $(20 \mathrm{~mL})$. The 
crude product was extracted with $\mathrm{CH}_{2} \mathrm{Cl}_{2}(3 \times 30 \mathrm{~mL})$, dried $\left(\mathrm{Na}_{2} \mathrm{SO}_{4}\right)$ and concentrated. The residue was purified by column chromatography on silica gel (5\% EtOAc : hexane) to afford $4(3.1 \mathrm{~g}, 75 \%)$ as viscous oil. IR (KBr): v 3312, 2997, 2929, 2266, 1632, 1377, 1222, 1162, 1074, $1016 \mathrm{~cm}^{-1} ;{ }^{1} \mathrm{H}$ NMR $\left(300 \mathrm{MHz}, \mathrm{CDCl}_{3}\right): \delta 5.52(\mathrm{~d}, J=3.7$ $\left.\mathrm{Hz}, 1 \mathrm{H}, \mathrm{C}_{1} \mathrm{H}\right), 4.59\left(\mathrm{t}, J=3.9 \mathrm{~Hz}, 1 \mathrm{H}, \mathrm{C}_{2} \mathrm{H}\right), 4.26(\mathrm{dt}, J=$ $\left.3.1,7.3 \mathrm{~Hz}, 1 \mathrm{H}, \mathrm{C}_{5} \mathrm{H}\right), 4.19\left(\mathrm{~s}, 2 \mathrm{H}, \mathrm{CH}_{2}\right), 4.07-3.94(\mathrm{~m}$, $\left.3 \mathrm{H}, \mathrm{C}_{4} \mathrm{H}, 2 \times \mathrm{C}_{6} \mathrm{H}\right), 3.65\left(\mathrm{dd}, J=8.9,4.1 \mathrm{~Hz}, 1 \mathrm{H}, \mathrm{C}_{3} \mathrm{H}\right)$, $3.16(\mathrm{~s}, 1 \mathrm{H}, \mathrm{CH}), 1.53\left(\mathrm{~s}, 3 \mathrm{H}, \mathrm{CH}_{3}\right), 1.40\left(\mathrm{~s}, 3 \mathrm{H}, \mathrm{CH}_{3}\right)$, $1.32\left(\mathrm{~s}, 6 \mathrm{H}, 2 \times \mathrm{CH}_{3}\right) ;{ }^{13} \mathrm{C} \mathrm{NMR}\left(75 \mathrm{MHz}, \mathrm{CDCl}_{3}\right): 112.5$, 109.4, 103.6, 80.1, 76.6, 75.2, 73.6, 65.2, 56.2, 25.6, 24.2. MS: $m / z\left(\mathrm{M}^{+}+\mathrm{Na}\right) 321$.

1-(4-Chlorophenyl)-4-(((3aS,4S,6R,6aS)-6-((R)-2,2-dimethyl-1,3-dioxolan-4-yl)-2,2-dimethyltetrahydrofuro[3,4- $d][1,3]$ dioxol-4-yloxy)methyl)-1H-1,2,3-triazole (3). To solution containing ( $3 \mathrm{~g}, 10.06 \mathrm{mmol})$ of the alkyne 4, $p$-chlorophenyl azide $(1.8 \mathrm{~g}, 11.76 \mathrm{mmol})$ in tetrahydrofuran $(30 \mathrm{~mL})$ and water $(1 \mathrm{~mL})$ were added $\mathrm{Cu}$ $\mathrm{SO}_{4} \cdot 5 \mathrm{H}_{2} \mathrm{O}(1.8 \mathrm{~g}, 8.15 \mathrm{mmol})$ and glucose $(0.2 \mathrm{~g})$. The resulting suspension was stirred at room temperature for 4-6 h. After this time, the mixture was diluted with $20 \mathrm{~m}$ $\mathrm{L} \mathrm{CH}_{2} \mathrm{Cl}_{2}$ and $20 \mathrm{~mL}$ water. The organic phase was separated, dried with sodium sulfate and concentrated at reduced pressure, the crude residue was purified by column chromatography silica gel (60-120 mesh, 35\% EtOAc : hexane) to afford $5(3.2 \mathrm{~g}, 75 \%)$ as a white powder. $\mathrm{mp}$ $149-151^{\circ} \mathrm{C}$. IR (KBr): v 3252, 2974, 2926, 1631, 1551, 1512, 1372, 1225, 1164, 1070, 1019, $734 \mathrm{~cm}^{-1}$; ${ }^{1} \mathrm{H}$ NMR $\left(300 \mathrm{MHz}, \mathrm{CDCl}_{3}\right): \delta 8.04(\mathrm{~s}, 1 \mathrm{H}, \mathrm{Ar}-\mathrm{H}), 7.55(\mathrm{~d}, J=9.2$ $\mathrm{Hz}, 2 \mathrm{H}, \mathrm{ArH}), 7.43$ (d, $J=8.9 \mathrm{~Hz}, 2 \mathrm{H}, \mathrm{Ar}-\mathrm{H}) 5.56(\mathrm{~d}, J=$ $\left.3.7 \mathrm{~Hz}, 1 \mathrm{H}, \mathrm{C}_{1} \mathrm{H}\right), 4.62\left(\mathrm{t}, J=3.9 \mathrm{~Hz}, 1 \mathrm{H}, \mathrm{C}_{2} \mathrm{H}\right), 4.55(\mathrm{~s}$, $\left.2 \mathrm{H}, \mathrm{CH}_{2}\right), 4.36\left(\mathrm{dt}, J=3.1,7.3 \mathrm{~Hz}, 1 \mathrm{H}, \mathrm{C}_{5} \mathrm{H}\right), 4.08-3.98$ $\left(\mathrm{m}, 3 \mathrm{H}, \mathrm{C}_{4} \mathrm{H}, 2 \times \mathrm{C}_{6} \mathrm{H}\right), 3.69(\mathrm{dd}, J=8.9,4.1 \mathrm{~Hz}, 1 \mathrm{H}$, $\left.\mathrm{C}_{3} \mathrm{H}\right), 1.52\left(\mathrm{~s}, 3 \mathrm{H}, \mathrm{CH}_{3}\right), 1.39\left(\mathrm{~s}, 3 \mathrm{H}, \mathrm{CH}_{3}\right), 1.33(\mathrm{~s}, 6 \mathrm{H}, 2$ $\left.\times \mathrm{CH}_{3}\right) ;{ }^{13} \mathrm{C} \mathrm{NMR}\left(75 \mathrm{MHz}, \mathrm{CDCl}_{3}\right): 143.6,133.6,122.1$, 118.9, 111.9, 108.6, 103.2, 80.0, 76.9, 73.9, 66.9, 65.9, 26.2, 25.9, 24.9. MS: $\mathrm{m} / z\left(\mathrm{M}^{+}+\mathrm{H}\right)$ 452. Anal. Calcd for $\mathrm{C}_{21} \mathrm{H}_{26} \mathrm{ClN}_{3} \mathrm{O}_{6}$ : C, 55.81; H, 5.80; N, 9.30. Found: C, $55.75 ; \mathrm{H}, 5.75 ; \mathrm{N}, 9.21$.

(R)-1-((3aS,4R,6S,6aS)-6-((1-(4-Chlorophenyl)-1H1,2,3-triazol-4-yl)methoxy)-2,2-dimethyltetrahydrofuro[3,4- $d][1,3]$ dioxol-4-yl)ethane-1,2-diol (4). A mixture of $3(3 \mathrm{~g}, 6.65 \mathrm{mmol})$ in $60 \%$ aq. AcOH $(25 \mathrm{~mL})$ was stirred at room temperature for $12 \mathrm{~h}$. Reaction mixture was neutralized with anhy. $\mathrm{NaHCO}_{3}(15 \mathrm{~g})$ and extracted with EtOAc $(3 \times 41 \mathrm{~mL})$. The combined organic layers were dried $\left(\mathrm{Na}_{2} \mathrm{SO}_{4}\right)$, evaporated and residue purified by column chromatography (60-120 mesh silica gel, $41 \%$ ethyl acetate in pet. ether) to afford $4(2.6 \mathrm{~g}, 82 \%)$ as a pale yellow solid; mp $168-171{ }^{\circ} \mathrm{C}$. IR (KBr) v 3218, 3486, 3362, 2992, 2965, 2936, 2922, 1630, 1544, 1510, 1212, 1161, $1022,732 \mathrm{~cm}^{-1} ;{ }^{1} \mathrm{H}$ NMR $\left(300 \mathrm{MHz}, \mathrm{CDCl}_{3}\right): \delta 8.01(\mathrm{~s}$, $1 \mathrm{H}, \mathrm{Ar}-\mathrm{H}), 7.51(\mathrm{~d}, J=9.2 \mathrm{~Hz}, 2 \mathrm{H}, \mathrm{ArH}), 7.40(\mathrm{~d}, J=8.9$
$\mathrm{Hz}, 2 \mathrm{H}, \mathrm{Ar}-\mathrm{H}) 5.49\left(\mathrm{~d}, J=3.7 \mathrm{~Hz}, 1 \mathrm{H}, \mathrm{C}_{1} \mathrm{H}\right), 4.52(\mathrm{t}, J=$ $\left.3.9 \mathrm{~Hz}, 1 \mathrm{H}, \mathrm{C}_{2} \mathrm{H}\right), 4.58\left(\mathrm{~s}, 2 \mathrm{H}, \mathrm{OCH}_{2}\right), 3.88-3.81(\mathrm{~m}, 2 \mathrm{H}$, $\left.\mathrm{C}_{4} \mathrm{H}, \mathrm{C}_{5} \mathrm{H}\right), 4.01-3.92\left(\mathrm{~m}, 3 \mathrm{H}, \mathrm{C}_{3} \mathrm{H}, 2 \times \mathrm{C}_{6} \mathrm{H}\right), 2.42$ (bs, $1 \mathrm{H}, \mathrm{OH}), 1.50\left(\mathrm{~s}, 3 \mathrm{H}, \mathrm{CH}_{3}\right), 1.45$ (bs, $\left.1 \mathrm{H}, \mathrm{OH}\right), 1.34$ (s, $\left.3 \mathrm{H}, \mathrm{CH}_{3}\right) ;{ }^{13} \mathrm{C}$ NMR $\left(75 \mathrm{MHz}, \mathrm{CDCl}_{3}\right): \delta 143.2,133.2$, 122.1, 117.2, 110.2, 109.2, 102.1, 78.8, 77.1, 75.1, 70.6, 67.2, 65.2, 63.2, 26.6, 26.2, 24.9. MS: $m / z\left(\mathrm{M}^{+}+\mathrm{H}\right) 412$. Anal. Calcd for $\mathrm{C}_{18} \mathrm{H}_{22} \mathrm{ClN}_{3} \mathrm{O}_{6}: \mathrm{C}, 52.49 ; \mathrm{H}, 5.38 ; \mathrm{N}$, 10.21. Found: C, 52.35; H, 5.25; N, 10.211.

2-((3aR,4S,6S,6aS)-6-((1-(4-Chlorophenyl)-1H-1,2,3triazol-4-yl)methoxy)-2,2-dimethyltetrahydrofuro[3,4d][1,3]dioxol-4-yl)-3-phenylthiazolidin-4-one 6a-g. To a solution of diol $4(0.200 \mathrm{~g}, 0.48 \mathrm{mmol})$ in $\mathrm{CH}_{2} \mathrm{Cl}_{2}(5 \mathrm{~m}-$ $\mathrm{L}), \mathrm{NaIO}_{4}(0.130 \mathrm{~g}, 0.61 \mathrm{mmol})$ was added at $0{ }^{\circ} \mathrm{C}$ and stirred at room temperature for $6 \mathrm{~h}$. The reaction mixture was filtered and washed with $\mathrm{CH}_{2} \mathrm{Cl}_{2}(2 \times 10 \mathrm{~mL})$. It was dried $\left(\mathrm{Na}_{2} \mathrm{SO}_{4}\right)$ and evaporated to give aldehyde $5(0.150$ $\mathrm{g}$ ) in quantitative yield as a yellow liquid, which was used as such for the next reaction.

To a stirred mixture of $5(0.150 \mathrm{~g}, 0.395 \mathrm{mmol})$, aromatic amine $(0.395 \mathrm{mmol})$ and anhydrous thioglycolic acid $(0.160 \mathrm{~g}, 0.211 \mathrm{mmol})$ in dry toluene $(5 \mathrm{~mL}), \mathrm{ZnCl}_{2}(0.100$ g, $0.751 \mathrm{mmol}$ ) was added after $2 \mathrm{~min}$ and irradiated in microwave bath reactor at $280 \mathrm{~W}$ for $4-7$ minutes at $110{ }^{\circ} \mathrm{C}$. After cooling, the filtrate was concentrated to dryness under reduced pressure and the residue was taken up in ethyl acetate. The ethyl acetate layer was washed with $5 \%$ sodium bicarbonate solution and finally with brine. The organic layer was dried over $\mathrm{Na}_{2} \mathrm{SO}_{4}$ and evaporated to dryness at reduced pressure. The crude product thus obtained was purified by column chromatography on silica gel $(60-120$ mesh) with hexane - ethyl acetate as eluent. Under conventional method the reaction mixture in toluene $(10 \mathrm{~mL})$ was refluxed at $110^{\circ} \mathrm{C}$ for the appropriate time (Table 1).

2-((3aR,4S,6S,6aS)-6-((1-(4-Chlorophenyl)-1H-1,2,3triazol-4-yl)methoxy)-2,2-dimethyltetrahydrofuro[3,4d] [1,3]dioxol-4-yl)-3-phenylthiazolidin-4-one (6a). mp $137-139^{\circ} \mathrm{C}$, IR (KBr) v 3422, 3210, 2984, 2972, 2934, 2831, 1712, 1610, 1541, 1512, 1414, 1225, $683 \mathrm{~cm}^{-1} ;{ }^{1} \mathrm{H}$ NMR (300 MHz, $\left.\mathrm{CDCl}_{3}\right): \delta 8.04(\mathrm{~s}, 1 \mathrm{H}, \mathrm{Ar}-\mathrm{H}), 7.50(\mathrm{~d}, J$ $=9.2 \mathrm{~Hz}, 2 \mathrm{H}, \mathrm{Ar}-\mathrm{H}), 7.39(\mathrm{~d}, J=8.9 \mathrm{~Hz}, 2 \mathrm{H}, \mathrm{Ar}-\mathrm{H})$, $7.42-6.95(5 \mathrm{H}, \mathrm{m}, \mathrm{Ar}-\mathrm{H}), 5.65\left(\mathrm{~d}, J=3.6 \mathrm{~Hz}, 1 \mathrm{H}, \mathrm{C}_{1} \mathrm{H}\right)$, $4.83(\mathrm{~d}, J=5.2 \mathrm{~Hz}, \mathrm{CH}-\mathrm{S}), 4.52\left(\mathrm{t}, J=3.9 \mathrm{~Hz}, 1 \mathrm{H}, \mathrm{C}_{2} \mathrm{H}\right)$, 4.48 (s, $\left.2 \mathrm{H}, \mathrm{OCH}_{2}\right), 3.98-3.95\left(\mathrm{~m}, 1 \mathrm{H}, \mathrm{C}_{4} \mathrm{H}\right), 3.65(\mathrm{~s}, 2 \mathrm{H}$, $\left.\mathrm{CH}_{2}\right), 3.29\left(\mathrm{dd}, J=9.1,4.2 \mathrm{~Hz}, 1 \mathrm{H}, \mathrm{C}_{3} \mathrm{H}\right), 1.50(\mathrm{~s}, 3 \mathrm{H}$, $\left.\mathrm{CH}_{3}\right), 1.29\left(\mathrm{~m}, 3 \mathrm{H}, \mathrm{CH}_{3}\right) ;{ }^{13} \mathrm{C} \mathrm{NMR}\left(75 \mathrm{MHz}, \mathrm{CDCl}_{3}\right): \delta$ $170.6,143.2,140.2,133.8,132.2,127.9,126.2,125.4$, 122.2, 118.6, 116.2, 104.8, 81.4, 78.2, 74.1, 65.9, 51.0, 33.6, 25.5; MS: $\mathrm{m} / z\left(\mathrm{M}^{+}+\mathrm{Na}\right)$ 552. Anal. Calcd for $\mathrm{C}_{25} \mathrm{H}_{25} \mathrm{ClN}_{4} \mathrm{O}_{5} \mathrm{~S}$ : C, 56.76; H, 4.76; N, 10.59. Found: $\mathrm{C}$, $56.53 ; \mathrm{H}, 4.55 ; \mathrm{N}, 10.43$.

3-(4-Chlorophenyl)-2-((3aR,4S,6S,6aS)-6-((1-(4-chlorophenyl)-1H-1,2,3-triazol-4-yl)methoxy)-2,2-di- 
methyltetrahydrofuro[3,4- $d][1,3]$ dioxol-4-yl)thiazolidin-4-one (6b). $\mathrm{mp} 206-208{ }^{\circ} \mathrm{C}$; IR (KBr) v 3420, 3219, 2974, 2962, 2812, 1710, 1610, 1546, 1510, 1409, 1219, $682 \mathrm{~cm}^{-1} ;{ }^{1} \mathrm{H}$ NMR $\left(300 \mathrm{MHz}, \mathrm{CDCl}_{3}\right): \delta 8.01(\mathrm{~s}, 1 \mathrm{H}, \mathrm{Ar}-$ $\mathrm{H}), 7.46(\mathrm{~d}, J=9.2 \mathrm{~Hz}, 4 \mathrm{H}, \mathrm{Ar}-\mathrm{H}), 7.41(\mathrm{~d}, J=8.9 \mathrm{~Hz}, 4 \mathrm{H}$, Ar-H), $5.62\left(\mathrm{~d}, J=3.6 \mathrm{~Hz}, 1 \mathrm{H}, \mathrm{C}_{1} \mathrm{H}\right), 4.84(\mathrm{~d}, J=5.2 \mathrm{~Hz}$, $\mathrm{CH}-\mathrm{S}), 4.50\left(\mathrm{t}, J=3.9 \mathrm{~Hz}, 1 \mathrm{H}, \mathrm{C}_{2} \mathrm{H}\right), 4.49\left(\mathrm{~s}, 2 \mathrm{H}, \mathrm{OCH}_{2}\right)$, $3.86-3.71\left(\mathrm{~m}, 1 \mathrm{H}, \mathrm{C}_{4} \mathrm{H}\right), 3.66\left(\mathrm{~s}, 2 \mathrm{H}, \mathrm{CH}_{2}\right), 3.29(\mathrm{dd}, J=$ 9.1, $\left.4.2 \mathrm{~Hz}, 1 \mathrm{H}, \mathrm{C}_{3} \mathrm{H}\right), 1.45\left(\mathrm{~s}, 3 \mathrm{H}, \mathrm{CH}_{3}\right), 1.32(\mathrm{~m}, 3 \mathrm{H}$, $\left.\mathrm{CH}_{3}\right) ;{ }^{13} \mathrm{C}$ NMR $\left(75 \mathrm{MHz}, \mathrm{CDCl}_{3}\right): 170.2,138.4,134.4$, 133.0, 128.4, 127.6, 125.2, 122.1, 118.4, 111.6, 104.3, 80.5, 74.1, 65.3, 52.1, 34.3, 25.5; MS: $\mathrm{m} / \mathrm{z}\left(\mathrm{M}^{+}+\mathrm{H}\right) 563$. Anal. Calcd for $\mathrm{C}_{25} \mathrm{H}_{24} \mathrm{Cl}_{2} \mathrm{~N}_{4} \mathrm{O}_{5} \mathrm{~S}$ : C, 53.29; H, 4.29; N, 9.94. Found: C, 53.21; H, 4.16; N, 9.83.

2-((3aR,4S,6S,6aS)-6-((1-(4-Chlorophenyl)-1H-1,2,3triazol-4-yl)methoxy)-2,2-dimethyltetrahydrofuro[3,4d][1,3]dioxol-4-yl)-3-(4-nitrophenyl)thiazolidin-4-one (6c). $\mathrm{mp} 201-205^{\circ} \mathrm{C}$; IR (KBr) $\vee 3422,3216,2984,2961$, 2820, 1710, 1605, 1536, 1512, 1416,1372, 1210, 863, 630 $\mathrm{cm}^{-1} ;{ }^{1} \mathrm{H}$ NMR $\left(300 \mathrm{MHz}, \mathrm{CDCl}_{3}\right): \delta 8.16(\mathrm{~d}, J=8.7 \mathrm{~Hz}$, 2H), $8.02(\mathrm{~s}, 1 \mathrm{H}, \mathrm{Ar}-\mathrm{H}), 7.49$ (d, $J=9.2 \mathrm{~Hz}, 2 \mathrm{H}, \mathrm{Ar}-\mathrm{H})$, $7.40(\mathrm{~d}, J=8.5 \mathrm{~Hz}, 2 \mathrm{H}, \mathrm{Ar}-\mathrm{H}), 6.72(\mathrm{~d}, J=9.8 \mathrm{~Hz}, 2 \mathrm{H}, \mathrm{Ar}-$ H), $5.69\left(\mathrm{~d}, J=3.6 \mathrm{~Hz}, 1 \mathrm{H}, \mathrm{C}_{1} \mathrm{H}\right), 4.86(\mathrm{~d}, J=5.2 \mathrm{~Hz}, \mathrm{CH}-$ $\mathrm{S}), 4.52\left(\mathrm{t}, J=3.9 \mathrm{~Hz}, 1 \mathrm{H}, \mathrm{C}_{2} \mathrm{H}\right), 4.49\left(\mathrm{~s}, 2 \mathrm{H}, \mathrm{OCH}_{2}\right)$, 3.86-3.81 (m, 1H, $\left.\mathrm{C}_{4} \mathrm{H}\right), 3.66\left(\mathrm{~s}, 2 \mathrm{H}, \mathrm{CH}_{2}\right), 3.24(\mathrm{dd}, J=$ 9.1, $\left.4.2 \mathrm{~Hz}, 1 \mathrm{H}, \mathrm{C}_{3} \mathrm{H}\right), 1.50\left(\mathrm{~s}, 3 \mathrm{H}, \mathrm{CH}_{3}\right), 1.24(\mathrm{~m}, 3 \mathrm{H}$, $\left.\mathrm{CH}_{3}\right) ;{ }^{13} \mathrm{C}$ NMR $\left(75 \mathrm{MHz}, \mathrm{CDCl}_{3}\right): \delta 170.2,145.5,143.4$, 142.2, 134.2, 130.2, 126.6, 124.3, 121.4, 118.8, 111.4, 104.6, 80.5, 77.2, 73.8, 66.4, 52.1, 34.2, 26.2; MS: $\mathrm{m} / \mathrm{z}$ $\left(\mathrm{M}^{+}+\mathrm{H}\right)$ 574. Anal. Calcd for $\mathrm{C}_{25} \mathrm{H}_{24} \mathrm{ClN}_{5} \mathrm{O}_{7} \mathrm{~S}: \mathrm{C}, 52.31$; $\mathrm{H}, 4.21 ; \mathrm{N}, 12.20$. Found: C, 52.26; H, 4.19; N, 12.11 .

2-((3aR,4S,6S,6aS)-6-((1-(4-Chlorophenyl)-1H-1,2,3triazol-4-yl)methoxy)-2,2-dimethyltetrahydrofuro[3,4d][1,3]dioxol-4-yl)-3-o-tolylthiazolidin-4-one (6d). mp $181-183{ }^{\circ} \mathrm{C}$; IR (KBr) v 3436, 3234, 2986, 2976, 2834 , $1710,1705,1610,1549,1516,1418,1262,865 \mathrm{~cm}^{-1} ;{ }^{1} \mathrm{H}$ NMR $\left(300 \mathrm{MHz}, \mathrm{CDCl}_{3}\right): \delta 8.13(\mathrm{~d}, J=8.7 \mathrm{~Hz}, 2 \mathrm{H}, \mathrm{Ar}-$ $\mathrm{H}), 8.01(\mathrm{~s}, 1 \mathrm{H}, \mathrm{Ar}-\mathrm{H}), 7.50(\mathrm{~d}, J=9.2 \mathrm{~Hz}, 2 \mathrm{H}, \mathrm{Ar}-\mathrm{H})$, 7.35-6.92 (m, 5H, Ar-H), $5.64\left(\mathrm{~d}, J=3.6 \mathrm{~Hz}, 1 \mathrm{H}, \mathrm{C}_{1} \mathrm{H}\right)$, $4.84(\mathrm{~d}, J=5.2 \mathrm{~Hz}, 1 \mathrm{H}, \mathrm{CH}-\mathrm{S}), 4.52(\mathrm{t}, J=3.9 \mathrm{~Hz}, 1 \mathrm{H}$, $\left.\mathrm{C}_{2} \mathrm{H}\right), 4.44\left(\mathrm{~s}, 2 \mathrm{H}, \mathrm{OCH}_{2}\right), 3.86-3.71\left(\mathrm{~m}, 1 \mathrm{H}, \mathrm{C}_{4} \mathrm{H}\right), 3.66$ $\left(\mathrm{s}, 2 \mathrm{H}, \mathrm{CH}_{2}\right), 3.16\left(\mathrm{dd}, J=9.1,4.2 \mathrm{~Hz}, 1 \mathrm{H}, \mathrm{C}_{3} \mathrm{H}\right), 2.08$ (s, $\left.3 \mathrm{H}, \mathrm{CH}_{3}\right), 1.49\left(\mathrm{~s}, 3 \mathrm{H}, \mathrm{CH}_{3}\right), 1.26\left(\mathrm{~m}, 3 \mathrm{H}, \mathrm{CH}_{3}\right) ;{ }^{13} \mathrm{C} \mathrm{NMR}$ $\left(75 \mathrm{MHz}, \mathrm{CDCl}_{3}\right): \delta 170.2,143.6,136.7,134.3,133.3$, 130.2, 129.1, 127.6, 125.2, 122.1, 118.8, 111.2, 104.4, 81.4, 78.3, 74.4, 66.1, 52.1, 26.2, 16.3; MS: $\mathrm{m} / \mathrm{z}\left(\mathrm{M}^{+}+\mathrm{H}\right)$ 545. Anal. Calcd for $\mathrm{C}_{26} \mathrm{H}_{27} \mathrm{ClN}_{4} \mathrm{O}_{5} \mathrm{~S}: \mathrm{C}, 57.51 ; \mathrm{H}, 5.51$; $\mathrm{N}, 10.32$. Found: C, 56.86; H, 5.39; N, 10.11 .

2-((3aR,4S,6S,6aS)-6-((1-(4-Chlorophenyl)-1H-1,2,3triazol-4-yl)methoxy)-2,2-dimethyltetrahydrofuro[3,4$d][1,3]$ dioxol-4-yl)-3-p-tolylthiazolidin-4-one (6e). $\mathrm{mp}$ $181-183{ }^{\circ} \mathrm{C}$; IR (KBr) v 3418, 3220, 2981, 2972, 2830, $1702,1691,1610,1536,1519,1412,1251,856 \mathrm{~cm}^{-1} ;{ }^{1} \mathrm{H}$
NMR (300 MHz, $\left.\mathrm{CDCl}_{3}\right): \delta 8.2(\mathrm{~d}, J=8.7 \mathrm{~Hz}, 2 \mathrm{H}, \mathrm{Ar}-\mathrm{H})$, $8.01(\mathrm{~s}, 1 \mathrm{H}, \mathrm{Ar}-\mathrm{H}), 7.44(\mathrm{~d}, J=9.2 \mathrm{~Hz}, 2 \mathrm{H}, \mathrm{Ar}-\mathrm{H}), 7.36$ (d, $J=8.3 \mathrm{~Hz}, 2 \mathrm{H}, \mathrm{Ar}-\mathrm{H}), 7.16(\mathrm{~d}, J=8.3 \mathrm{~Hz}, 2 \mathrm{H}, \mathrm{Ar}-\mathrm{H}), 5.66$ $\left(\mathrm{d}, J=3.6 \mathrm{~Hz}, 1 \mathrm{H}, \mathrm{C}_{1} \mathrm{H}\right), 4.86(\mathrm{~d}, J=5.2 \mathrm{~Hz}, 1 \mathrm{H}, \mathrm{CH}-\mathrm{S})$, $4.56\left(\mathrm{t}, J=3.9 \mathrm{~Hz}, 1 \mathrm{H}, \mathrm{C}_{2} \mathrm{H}\right), 4.54\left(\mathrm{~s}, 2 \mathrm{H}, \mathrm{OCH}_{2}\right)$, $3.86-3.81\left(\mathrm{~m}, 1 \mathrm{H}, \mathrm{C}_{4} \mathrm{H}\right), 3.66\left(\mathrm{~s}, 2 \mathrm{H}, \mathrm{CH}_{2}\right), 3.16(\mathrm{dd}, J=$ 9.1, $\left.4.2 \mathrm{~Hz}, 1 \mathrm{H}, \mathrm{C}_{3} \mathrm{H}\right), 2.32\left(\mathrm{~s}, 3 \mathrm{H}, \mathrm{CH}_{3}\right), 1.43(\mathrm{~s}, 3 \mathrm{H}$, $\left.\mathrm{CH}_{3}\right), 1.36\left(\mathrm{~m}, 3 \mathrm{H}, \mathrm{CH}_{3}\right) ;{ }^{13} \mathrm{C} \mathrm{NMR}\left(75 \mathrm{MHz}, \mathrm{CDCl}_{3}\right): \delta$ 171.6, 143.1, 136.4, 131.6, 130.3, 129.2, 128.2, 127.9, 124.2, 122.1, 118.2, 110.2, 103.1, 80.9, 78.3, 74.6, 64.9, 51.6, 26.4,15.1; MS: $\mathrm{m} / \mathrm{z}\left(\mathrm{M}^{+}+\mathrm{Na}\right)$ 565. Anal. Calcd for $\mathrm{C}_{26} \mathrm{H}_{27} \mathrm{ClN}_{4} \mathrm{O}_{5} \mathrm{~S}: \mathrm{C}, 57.51 ; \mathrm{H}, 5.51 ; \mathrm{N}, 10.32$. Found: C, $56.82 ; \mathrm{H}, 5.35 ; \mathrm{N}, 10.09$.

2-((3aR,4S,6S,6aS)-6-((1-(4-Chlorophenyl)-1H-1,2,3triazol-4-yl)methoxy)-2,2-dimethyltetrahydrofuro[3,4$d][1,3]$ dioxol-4-yl)-3-(3-hydroxyphenyl)thiazolidin-4one (6f). mp $218-219^{\circ} \mathrm{C}$; IR (KBr) v 3525, 3416, 3231, 2975, 2964, 2822, 1710, 1610, 1546,1512, 1416, 1259, $861 \mathrm{~cm}^{-1}$; ${ }^{1} \mathrm{H}$ NMR $\left(300 \mathrm{MHz}, \mathrm{CDCl}_{3}\right): \delta 8.16(\mathrm{~d}, J=8.7$ $\mathrm{Hz}, 2 \mathrm{H}, \mathrm{Ar}-\mathrm{H}), 8.01$ (s, 1H, Ar-H), $7.46(\mathrm{~d}, J=9.2 \mathrm{~Hz}, 2 \mathrm{H}$, Ar-H), 7.04-6.90 (m, 4H, Ar-H), $5.72(\mathrm{~d}, J=3.6 \mathrm{~Hz}, 1 \mathrm{H}$, $\left.\mathrm{C}_{1} \mathrm{H}\right), 5.30(\mathrm{~s}, 1 \mathrm{H}, \mathrm{OH}), 4.86(\mathrm{~d}, J=5.2 \mathrm{~Hz}, 1 \mathrm{H}, \mathrm{CH}-\mathrm{S})$, $4.56\left(\mathrm{t}, J=3.9 \mathrm{~Hz}, 1 \mathrm{H}, \mathrm{C}_{2} \mathrm{H}\right), 4.50\left(\mathrm{~s}, 2 \mathrm{H}, \mathrm{OCH}_{2}\right)$, 3.91-3.89 (m, $\left.1 \mathrm{H}, \mathrm{C}_{4} \mathrm{H}\right), 3.71\left(\mathrm{~s}, 2 \mathrm{H}, \mathrm{CH}_{2}\right), 3.22(\mathrm{dd}, J=$ 9.1, $\left.4.2 \mathrm{~Hz}, 1 \mathrm{H}, \mathrm{C}_{3} \mathrm{H}\right), 1.50\left(\mathrm{~s}, 3 \mathrm{H}, \mathrm{CH}_{3}\right), 1.36(\mathrm{~m}, 3 \mathrm{H}$, $\left.\mathrm{CH}_{3}\right) ;{ }^{13} \mathrm{C}$ NMR $\left(75 \mathrm{MHz}, \mathrm{CDCl}_{3}\right): \delta 171.2,157.3,144.0$, 143.6, 133.6, 132.4, 130.6, 128.3, 121.2, 120.4, 119.3, 113.6, 111.1, 107.6, 106.8, 81.8, 77.6, 74.8, 63.9, 54.4, 41.2, 34.3; MS: $\mathrm{m} / \mathrm{z}\left(\mathrm{M}^{+}+\mathrm{H}\right)$ 545. Anal. Calcd for $\mathrm{C}_{25} \mathrm{H}_{25} \mathrm{ClN}_{4} \mathrm{O}_{6} \mathrm{~S}: \mathrm{C}, 55.09 ; \mathrm{H}, 4.62 ; \mathrm{N}, 10.28$. Found: $\mathrm{C}$, $54.82 ; \mathrm{H}, 4.55 ; \mathrm{N}, 10.19$.

2-((3aR,4S,6S,6aS)-6-((1-(4-Chlorophenyl)-1H-1,2,3triazol-4-yl)methoxy)-2,2-dimethyltetrahydrofuro[3,4$d][1,3]$ dioxol-4-yl)-3-(4-hydroxyphenyl)thiazolidin-4one (6g). $\mathrm{mp} 253-255^{\circ} \mathrm{C}$; IR ( $\left.\mathrm{KBr}\right) \vee 3531,3415,3222$, 2977, 2960, 2832, 1710, 1614, 1536,1509, 1412, 1248, $860 \mathrm{~cm}^{-1} ;{ }^{1} \mathrm{H}$ NMR $\left(300 \mathrm{MHz}, \mathrm{CDCl}_{3}\right): \delta 8.20(\mathrm{~d}, J=8.7$ $\mathrm{Hz}, 2 \mathrm{H}, \mathrm{Ar}-\mathrm{H}), 8.02$ (s, $1 \mathrm{H}, \mathrm{Ar}-\mathrm{H}), 7.51(\mathrm{~d}, J=9.2 \mathrm{~Hz}, 2 \mathrm{H}$, Ar-H), 7.02-6.90 (m, 4H, Ar-H), $5.56(\mathrm{~d}, J=3.6 \mathrm{~Hz}, 1 \mathrm{H}$, $\left.\mathrm{C}_{1} \mathrm{H}\right), 5.18(\mathrm{~s}, 1 \mathrm{H}, \mathrm{OH}), 4.90(\mathrm{~d}, J=5.2 \mathrm{~Hz}, 1 \mathrm{H}, \mathrm{CH}-\mathrm{S})$, $4.60\left(\mathrm{t}, J=3.9 \mathrm{~Hz}, 1 \mathrm{H}, \mathrm{C}_{2} \mathrm{H}\right), 4.49\left(\mathrm{~s}, 2 \mathrm{H}, \mathrm{OCH}_{2}\right)$, 3.81-3.79 (m, 1H, $\left.\mathrm{C}_{4} \mathrm{H}\right), 3.69\left(\mathrm{~s}, 2 \mathrm{H}, \mathrm{CH}_{2}\right), 3.24(\mathrm{dd}, J=$ 9.1, $\left.4.2 \mathrm{~Hz}, 1 \mathrm{H}, \mathrm{C}_{3} \mathrm{H}\right), 1.50\left(\mathrm{~s}, 3 \mathrm{H}, \mathrm{CH}_{3}\right), 1.26(\mathrm{~m}, 3 \mathrm{H}$, $\left.\mathrm{CH}_{3}\right) ;{ }^{13} \mathrm{C}$ NMR $\left(75 \mathrm{MHz}, \mathrm{CDCl}_{3}\right): \delta 170.2,156.8,143.2$, $142.2,132.9,131.4,130.2,127.6,121.9,120.5,119.8$, 114.2, 111.2, 106.4, 81.4, 78.1, 73.5, 62.4, 54.2, 40.3, 34.6; MS: $m / z\left(\mathrm{M}^{+}+\mathrm{H}\right)$ 545. Anal. Calcd for $\mathrm{C}_{25} \mathrm{H}_{25} \mathrm{Cl}-$ $\mathrm{N}_{4} \mathrm{O}_{6} \mathrm{~S}: \mathrm{C}, 55.09 ; \mathrm{H}, 4.62 ; \mathrm{N}, 10.28$. Found: C, 54.92; H, $4.59 ; \mathrm{N}, 10.22$.

2-(2-((3aR,4S,6S,6aS)-6-((1-(4-Chlorophenyl)-1H1,2,3-triazol-4-yl)methoxy)-2,2-dimethyltetrahydrofuro[3,4-d][1,3]dioxol-4-yl)-4-oxo-3-phenylthiazolidin-5yl)acetic acid 7a-g. To a solution of diol 5 ( 0.200 g, 0.48 
mmol) in $\mathrm{CH}_{2} \mathrm{Cl}_{2}(5 \mathrm{~mL}), \mathrm{NaIO}_{4}(0.130 \mathrm{~g}, 0.61 \mathrm{mmol})$ was added at $0{ }^{\circ} \mathrm{C}$ and stirred at room temperature for $6 \mathrm{~h}$. The reaction mixture was filtered and washed with $\mathrm{CH}_{2} \mathrm{Cl}_{2}(2 \times 10 \mathrm{~mL})$. It was dried $\left(\mathrm{Na}_{2} \mathrm{SO}_{4}\right)$ and evaporated to give aldehyde $7(0.150 \mathrm{~g})$ in quantitative yield as a yellow liquid, which was used as such for the next reaction.

To a stirred mixture of $7(0.150 \mathrm{~g}, 0.395 \mathrm{mmol})$, aromatic amine $(0.395 \mathrm{mmol})$ and thiomalic acid $(0.125 \mathrm{~g}$, $0.86 \mathrm{mmol})$ in dry toluene $(5 \mathrm{~mL})$, anhydrous $\mathrm{ZnCl}_{2}$ $(0.100 \mathrm{~g}, 0.751 \mathrm{mmol})$ was added after $2 \mathrm{~min}$ and irradiated in microwave bath reactor at $280 \mathrm{~W}$ for $4-7$ minutes at $110^{\circ} \mathrm{C}$. After cooling, the filtrate was concentrated to dryness under reduced pressure and the residue was taken up in ethyl acetate. The ethyl acetate layer was washed with $5 \%$ sodium bicarbonate solution and finally with brine. The organic layer was dried over $\mathrm{Na}_{2} \mathrm{SO}_{4}$ and evaporated to dryness at reduced pressure. The crude product thus obtained was purified by column chromatography on silica gel (60-120 mesh) with hexane - ethyl acetate as eluent. Under conventional method the reaction mixture in toluene $(10 \mathrm{~mL})$ was refluxed at $110^{\circ} \mathrm{C}$ for the appropriate time (Table 1).

2-(2-((3aR,4S,6S,6aS)-6-((1-(4-Chlorophenyl)-1H1,2,3-triazol-4-yl)methoxy)-2,2-dimethyltetrahydrofuro[3,4-d][1,3]dioxol-4-yl)-4-oxo-3-phenylthiazolidin-5-yl)acetic acid (7a). mp211-214 ${ }^{\circ} \mathrm{C}$ IR (KBr) v 3434, 3221, 2984, 2970, 2940, 2822, 1722, 1610, 1539, 1512, 1410, 1214, $684 \mathrm{~cm}^{-1}$; ${ }^{1} \mathrm{H}$ NMR $(300 \mathrm{MHz}, \mathrm{CDC}-$ $\left.1_{3}\right): \delta 11.34\left(\mathrm{~s}, 1 \mathrm{H}, \mathrm{CO}_{2} \mathrm{H}\right), 8.05(\mathrm{~s}, 1 \mathrm{H}, \mathrm{Ar}-\mathrm{H}), 7.45(\mathrm{~d}, J$ $=9.2 \mathrm{~Hz}, 2 \mathrm{H}, \mathrm{Ar}-\mathrm{H}), 7.38(\mathrm{~d}, J=8.9 \mathrm{~Hz}, 2 \mathrm{H}, \mathrm{Ar}-\mathrm{H})$, 7.32-7.28 (m, 5H, Ar -H), 6.05 (s,1H, CHS), 5.53 (d, $J=$ $\left.4.2 \mathrm{~Hz}, 1 \mathrm{H}, \mathrm{C}_{1} \mathrm{H}\right), 4.59\left(\mathrm{t}, J=3.9 \mathrm{~Hz}, 1 \mathrm{H}, \mathrm{C}_{2} \mathrm{H}\right), 4.55(\mathrm{t}$, $1 \mathrm{H}, \mathrm{CH}), 4.42\left(\mathrm{~s}, 2 \mathrm{H}, \mathrm{OCH}_{2}\right), 3.82-3.79\left(\mathrm{~m}, 1 \mathrm{H}, \mathrm{C}_{4} \mathrm{H}\right)$, $3.21\left(\mathrm{dd}, J=9.1,4.2 \mathrm{~Hz}, 1 \mathrm{H}, \mathrm{C}_{3} \mathrm{H}\right), 2.28\left(\mathrm{~d}, 2 \mathrm{H}, \mathrm{CH}_{2}\right)$, $1.43\left(\mathrm{~s}, 3 \mathrm{H}, \mathrm{CH}_{3}\right), 1.20\left(\mathrm{~m}, 3 \mathrm{H}, \mathrm{CH}_{3}\right) ;{ }^{13} \mathrm{C}$ NMR $(75$ $\left.\mathrm{MHz}, \mathrm{CDCl}_{3}\right): \delta 170.3,143.2,140.2,133.2,126.2,124.8$, 121.9, 117.8, 103.2, 80.1, 76.9, 72.8, 65.1, 50.0, 36.2, 32.9, 24.9; MS: $\mathrm{m} / \mathrm{z}\left(\mathrm{M}^{+}+\mathrm{H}\right)$ 545. Anal. Calcd for $\mathrm{C}_{27} \mathrm{H}_{27} \mathrm{ClN}_{4} \mathrm{O}_{7} \mathrm{~S}$ : C, 55.24; H, 4.64; N, 9.54. Found: C, $55.12 ; \mathrm{H}, 4.59 ; \mathrm{N}, 9.39$.

2-(3-(4-Chlorophenyl)-2-((3aR,4S,6S,6aS)-6-((1-)(4chlorophenyl)-1H-1,2,3-triazol-4-yl)methoxy)-2,2-dimethyltetrahydrofuro $[3,4-d][1,3]$ dioxol-4-yl)-4-oxothiazolidin-5-yl)acetic acid (7b). mp $249-251{ }^{\circ} \mathrm{C}$; IR $(\mathrm{KBr}) \vee 3428,3421,3216,2972,2819,1721,1715,1606$, 1529, 1509, 1410, 1206, $679 \mathrm{~cm}^{-1}$; ${ }^{1} \mathrm{H}$ NMR $(300 \mathrm{MHz}$, $\left.\mathrm{CDCl}_{3}\right): \delta 11.24\left(\mathrm{~s}, 1 \mathrm{H}, \mathrm{CO}_{2} \mathrm{H}\right), 7.88(\mathrm{~s}, 1 \mathrm{H}, \mathrm{Ar}-\mathrm{H}), 7.35$ (d, $J=9.2 \mathrm{~Hz}, 4 \mathrm{H}, \mathrm{Ar}-\mathrm{H}), 7.39$ (d, $J=8.9 \mathrm{~Hz}, 4 \mathrm{H}, \mathrm{Ar}-\mathrm{H})$, $6.10(\mathrm{~s}, 1 \mathrm{H}, \mathrm{CHS}), 5.78\left(\mathrm{~d}, J=4.2 \mathrm{~Hz}, 1 \mathrm{H}, \mathrm{C}_{1} \mathrm{H}\right), 4.72(\mathrm{t}$, $\left.J=3.9 \mathrm{~Hz}, 1 \mathrm{H}, \mathrm{C}_{2} \mathrm{H}\right), 4.55(\mathrm{t}, 1 \mathrm{H}, \mathrm{CH}), 4.52(\mathrm{~s}, 2 \mathrm{H}$, $\left.\mathrm{OCH}_{2}\right), 3.92-3.89\left(\mathrm{~m}, 1 \mathrm{H}, \mathrm{C}_{4} \mathrm{H}\right), 3.20(\mathrm{dd}, J=9.1,4.2 \mathrm{~Hz}$, $\left.1 \mathrm{H}, \mathrm{C}_{3} \mathrm{H}\right), 2.34\left(\mathrm{~d}, 2 \mathrm{H}, \mathrm{CH}_{2}\right), 1.53\left(\mathrm{~s}, 3 \mathrm{H}, \mathrm{CH}_{3}\right), 1.30(\mathrm{~m}$, $\left.3 \mathrm{H}, \mathrm{CH}_{3}\right) ;{ }^{13} \mathrm{C}$ NMR $\left(75 \mathrm{MHz}, \mathrm{CDCl}_{3}\right): \delta 170.4,142.2$,
$141.6,132.6,127.8,125.9,121.2,117.4,103.5,80.4$, 77.23, 71.2, 66.1, 51.3, 35.9, 31.2, 24.6; $\mathrm{MS}: \mathrm{m} / \mathrm{z}\left(\mathrm{M}^{+}+\mathrm{H}\right)$ 621. Anal. Calcd for $\mathrm{C}_{27} \mathrm{H}_{26} \mathrm{Cl}_{2} \mathrm{~N}_{4} \mathrm{O}_{7} \mathrm{~S}: \mathrm{C}, 52.18 ; \mathrm{H}, 4.22$; N, 9.01. Found: C, 52.02; H, 4.09; N, 8.95

2-(2-((3aR,4S,6S,6aS)-6-((1-(4-Chlorophenyl)- $1 H$ 1,2,3-triazol-4-yl)methoxy)-2,2-dimethyltetrahydrofuro[3,4-d][1,3]dioxol-4-yl)-3-(4-nitrophenyl)-4-oxothiazolidin-5-yl)aceticacid (7c). $\mathrm{mp} 266-268{ }^{\circ} \mathrm{C}$, IR ( $\left.\mathrm{KBr}\right) \mathrm{v}$ 3418, 3424, 3215, 2971, 2986, 2819, 1722, 1710, 1606, 1526, 1510, 1409, 1363, 1210, 861, $635 \mathrm{~cm}^{-1} ;{ }^{1} \mathrm{H}$ NMR $\left(300 \mathrm{MHz}, \mathrm{CDCl}_{3}\right): \delta 11.42\left(\mathrm{~s}, 1 \mathrm{H}, \mathrm{CO}_{2} \mathrm{H}\right), 8.11(\mathrm{~d}, J=$ $8.4 \mathrm{~Hz}, 2 \mathrm{H}), 8.01(\mathrm{~s}, 1 \mathrm{H}, \mathrm{Ar}-\mathrm{H}), 7.45(\mathrm{~d}, J=9.1 \mathrm{~Hz}, 2 \mathrm{H}$, Ar-H), $7.41(\mathrm{~d}, J=8.5 \mathrm{~Hz}, 2 \mathrm{H}, \mathrm{Ar}-\mathrm{H}), 6,79(\mathrm{~d}, J=9.6 \mathrm{~Hz}$, $2 \mathrm{H}, \mathrm{Ar}-\mathrm{H}), 6.14(\mathrm{~s}, 1 \mathrm{H}, \mathrm{CHS}), 5.69(\mathrm{~d}, J=4.2 \mathrm{~Hz}, 1 \mathrm{H}$, $\left.\mathrm{C}_{1} \mathrm{H}\right), 4.65(\mathrm{t}, 1 \mathrm{H}, \mathrm{CH}), 4.53\left(\mathrm{t}, J=3.9 \mathrm{~Hz}, 1 \mathrm{H}, \mathrm{C}_{2} \mathrm{H}\right), 4.52$ (s, $\left.2 \mathrm{H}, \mathrm{OCH}_{2}\right), 3.90-3.86\left(\mathrm{~m}, 1 \mathrm{H}, \mathrm{C}_{4} \mathrm{H}\right), 3.19(\mathrm{dd}, J=9.1$, $\left.4.2 \mathrm{~Hz}, 1 \mathrm{H}, \mathrm{C}_{3} \mathrm{H}\right), 2.30\left(\mathrm{~d}, 2 \mathrm{H}, \mathrm{CH}_{2}\right), 1.49\left(\mathrm{~s}, 3 \mathrm{H}, \mathrm{CH}_{3}\right)$, $1.25\left(\mathrm{~m}, 3 \mathrm{H}, \mathrm{CH}_{3}\right) ;{ }^{13} \mathrm{C}$ NMR $\left(75 \mathrm{MHz}, \mathrm{CDCl}_{3}\right): \delta 190.2$, 173.2, 143.6, 141.9, 134.5, 128.2, 126.5, 122.2, 118.2, 104.3, 80.4, 77.2, 73.1, 66.2, 52.1, 36.4, 33.1, 25.4; MS: $\mathrm{m} / \mathrm{z}\left(\mathrm{M}^{+}+\mathrm{H}\right)$ 632. Anal. Calcd for $\mathrm{C}_{27} \mathrm{H}_{26} \mathrm{Cl}_{2} \mathrm{~N}_{5} \mathrm{O}_{9} \mathrm{~S}: \mathrm{C}$, 51.31; H, 4.15; N, 11.08. Found: C, 51.19; H, 4.09; N, 10.95 .

2-(2-((3aR,4S,6S,6aS)-6-((1-(4-Chlorophenyl)-1H1,2,3-triazol-4-yl)methoxy)-2,2-dimethyltetrahydrofuro[3,4- $d][1,3]$ dioxol-4-yl)-4-oxo-3-o-tolylthiazolidin-5yl)aceticacid (7d). mp $247-249{ }^{\circ} \mathrm{C}$; IR (KBr) v 3429 , 3219, 2968, 2831, 1704, 1689, 1610, 1549, 1512, 1415, $1260,850 \mathrm{~cm}^{-1} ;{ }^{1} \mathrm{H}$ NMR $\left(300 \mathrm{MHz}, \mathrm{CDCl}_{3}\right): \delta 11.42(\mathrm{~s}$, $\left.1 \mathrm{H}, \mathrm{CO}_{2} \mathrm{H}\right), 8.20(\mathrm{~d}, J=8.4 \mathrm{~Hz}, 2 \mathrm{H}, \mathrm{Ar}-\mathrm{H}), 8.02(\mathrm{~s}, 1 \mathrm{H}$, Ar-H), $7.48(\mathrm{~d}, J=9.1 \mathrm{~Hz}, 2 \mathrm{H}, \mathrm{Ar}-\mathrm{H}), 7.32-6.95(\mathrm{~m}, 4 \mathrm{H}$, Ar-H), 6.09 (s, 1H, CHS), 5.55 (d, $J=4.2 \mathrm{~Hz}, 1 \mathrm{H}, \mathrm{C}_{1} \mathrm{H}$ ), $4.50(\mathrm{t}, 1 \mathrm{H}, \mathrm{CH}), 4.48\left(\mathrm{t}, J=3.9 \mathrm{~Hz}, 1 \mathrm{H}, \mathrm{C}_{2} \mathrm{H}\right), 4.44(\mathrm{~s}$, $\left.2 \mathrm{H}, \mathrm{OCH}_{2}\right), 3.82-3.76\left(\mathrm{~m}, 1 \mathrm{H}, \mathrm{C}_{4} \mathrm{H}\right), 3.12(\mathrm{dd}, J=9.1,4.2$ $\left.\mathrm{Hz}, 1 \mathrm{H}, \mathrm{C}_{3} \mathrm{H}\right), 2.24\left(\mathrm{~d}, 2 \mathrm{H}, \mathrm{CH}_{2}\right), 2.19\left(\mathrm{~s}, 3 \mathrm{H}, \mathrm{CH}_{3}\right), 1.49$ $\left(\mathrm{s}, 3 \mathrm{H}, \mathrm{CH}_{3}\right), 1.19\left(\mathrm{~m}, 3 \mathrm{H}, \mathrm{CH}_{3}\right) ;{ }^{13} \mathrm{C} \mathrm{NMR}(75 \mathrm{MHz}$, $\left.\mathrm{CDCl}_{3}\right): 190.4,172.4,143.6,141.9,132.9,124.4,122.2$, 118.2, 104.6, 80.2, 76.4, 72.4, 65.5, 52.1, 35.3, 32.2, 24.2,16.1; MS: $\mathrm{m} / \mathrm{z}\left(\mathrm{M}^{+}+\mathrm{H}\right)$ 600. Anal. Calcd for $\mathrm{C}_{28} \mathrm{H}_{29} \mathrm{ClN}_{4} \mathrm{O}_{7} \mathrm{~S}: \mathrm{C}, 55.95 ; \mathrm{H}, 4.86 ; \mathrm{N}, 9.32$. Found: $\mathrm{C}$, $54.19 ; \mathrm{H}, 4.62 ; \mathrm{N}, 9.15$.

2-(2-((3aR,4S,6S,6aS)-6-((1-(4-Chlorophenyl)-1H1,2,3-triazol-4-yl)methoxy)-2,2-dimethyltetrahydrofuro[3,4- $d][1,3]$ dioxol-4-yl)-4-oxo-3-p-tolylthiazolidin5-yl)acetic acid (7e). $\mathrm{mp} 187-189{ }^{\circ} \mathrm{C}$; IR (KBr) $\vee 3425$, 3229, 2961, 2820, 1709, 1686, 1615, 1545, 1510, 1424, $1253,840 \mathrm{~cm}^{-1}$; ${ }^{1} \mathrm{H}$ NMR $\left(300 \mathrm{MHz}, \mathrm{CDCl}_{3}\right): \delta 11.35$ (s, $\left.1 \mathrm{H}, \mathrm{CO}_{2} \mathrm{H}\right), 8.19(\mathrm{~d}, J=8.4 \mathrm{~Hz}, 2 \mathrm{H}, \mathrm{Ar}-\mathrm{H}), 8.01(\mathrm{~s}, 1 \mathrm{H}$, Ar-H), 7.51 (d, $J=9.1 \mathrm{~Hz}, 2 \mathrm{H}, \mathrm{Ar}-\mathrm{H}), 7.26$ (d, $J=8.33$ $\mathrm{Hz}, 2 \mathrm{H}, \mathrm{Ar}-\mathrm{H}), 7.10$ (d, $J=8.3 \mathrm{~Hz}, 2 \mathrm{H}, \mathrm{Ar}-\mathrm{H}), 6.11$ (s, $1 \mathrm{H}, \mathrm{CHS}), 5.60\left(\mathrm{~d}, J=4.2 \mathrm{~Hz}, 1 \mathrm{H}, \mathrm{C}_{1} \mathrm{H}\right), 4.50(\mathrm{t}, 1 \mathrm{H}$, $\mathrm{CH}), 4.43\left(\mathrm{t}, J=3.9 \mathrm{~Hz}, 1 \mathrm{H}, \mathrm{C}_{2} \mathrm{H}\right), 4.34\left(\mathrm{~s}, 2 \mathrm{H}, \mathrm{OCH}_{2}\right)$, $3.82-3.76\left(\mathrm{~m}, 1 \mathrm{H}, \mathrm{C}_{4} \mathrm{H}\right), 3.12(\mathrm{dd}, J=9.1,4.2 \mathrm{~Hz}, 1 \mathrm{H}$, 
$\left.\mathrm{C}_{3} \mathrm{H}\right), 2.32\left(\mathrm{~d}, 2 \mathrm{H}, \mathrm{CH}_{2}\right), 2.16\left(\mathrm{~s}, 3 \mathrm{H}, \mathrm{CH}_{3}\right), 1.47(\mathrm{~s}, 3 \mathrm{H}$, $\left.\mathrm{CH}_{3}\right), 1.19\left(\mathrm{~m}, 3 \mathrm{H}, \mathrm{CH}_{3}\right) ;{ }^{13} \mathrm{C}$ NMR $\left(75 \mathrm{MHz}, \mathrm{CDCl}_{3}\right)$ : 190.4, 172.4, 143.6, 141.9, 132.9, 124.4, 121.2, 117.2, 103.6, 80.6, 76.4, 72.4, 65.5, 52.1, 35.3, 32.2, 24.2, 15.2; MS: $m / z\left(\mathrm{M}^{+}+\mathrm{H}\right)$ 600. Anal. Calcd for $\mathrm{C}_{28} \mathrm{H}_{29} \mathrm{ClN}_{4} \mathrm{O}_{7} \mathrm{~S}$ : C, 55.95; H, 4.86; N, 9.32. Found: C, 54.19; H, 4.62; N, 9.15 .

2-(2-((3a $R, 4 S, 6 S, 6 \mathrm{a} S)-6-((1-(4-C h l o r o p h e n y))-1 H-$ 1,2,3-triazol-4-yl)methoxy)-2,2-dimethyltetrahydrofuro[3,4- $d][1,3]$ dioxol-4-yl)-3-(3-hydroxyphenyl)-4-oxothiazolidin-5-yl)acetic acid (7f). mp 237-239 ${ }^{\circ} \mathrm{C}$; IR $(\mathrm{KBr})$ v 3525, 3426, 3216, 2965, 2830, 1710, 1612, $1534,1514,1414,1251,861 \mathrm{~cm}^{-1} ;{ }^{1} \mathrm{H}$ NMR $(300 \mathrm{MHz}$, $\left.\mathrm{CDCl}_{3}\right): \delta 11.32\left(\mathrm{~s}, 1 \mathrm{H}, \mathrm{CO}_{2} \mathrm{H}\right), 8.21(\mathrm{~d}, J=8.7 \mathrm{~Hz}, 2 \mathrm{H}$, Ar-H), 8.01 (s, 1H, Ar-H), $7.51(\mathrm{~d}, J=9.2 \mathrm{~Hz}, 2 \mathrm{H}, \mathrm{Ar}-\mathrm{H})$, 7.04-6.90 (m, 4H, Ar-H), 6.11 (s, 1H, CHS), 5.66 (d, $J=$ $\left.3.6 \mathrm{~Hz}, 1 \mathrm{H}, \mathrm{C}_{1} \mathrm{H}\right), 5.32(\mathrm{~s}, 1 \mathrm{H}, \mathrm{OH}), 4.86(\mathrm{~d}, J=5.2 \mathrm{~Hz}$, $1 \mathrm{H}, \mathrm{CH}), 4.49\left(\mathrm{t}, J=3.9 \mathrm{~Hz}, 1 \mathrm{H}, \mathrm{C}_{2} \mathrm{H}\right), 4.34(\mathrm{~s}, 2 \mathrm{H}$, $\left.\mathrm{OCH}_{2}\right), 3.83-3.76\left(\mathrm{~m}, 1 \mathrm{H}, \mathrm{C}_{4} \mathrm{H}\right), 3.26(\mathrm{dd}, J=9.1,4.2 \mathrm{~Hz}$, $\left.1 \mathrm{H}, \mathrm{C}_{3} \mathrm{H}\right), 2.24\left(\mathrm{~d}, 2 \mathrm{H}, \mathrm{CH}_{2}\right), 1.43\left(\mathrm{~s}, 3 \mathrm{H}, \mathrm{CH}_{3}\right), 1.28(\mathrm{~m}$, $\left.3 \mathrm{H}, \mathrm{CH}_{3}\right) ;{ }^{13} \mathrm{C}$ NMR $\left(75 \mathrm{MHz}, \mathrm{CDCl}_{3}\right): 174.6,171.1$, 157.3, 143.2, 143.1, 133.6, 133.4, 131.6, 127.6, 121.2, 120.1, 119.1, 114.2, 111.2, 107.2, 106.2, 81.2, 78.2, 74.1, 64.3, 54.2, 41.0, 38.2, 35.1; MS: $m / z\left(\mathrm{M}^{+}+\mathrm{H}\right)$ 545. Anal. Calcd for $\mathrm{C}_{27} \mathrm{H}_{27} \mathrm{ClN}_{4} \mathrm{O}_{8} \mathrm{~S}: \mathrm{C}, 53.78 ; \mathrm{H}, 4.52 ; \mathrm{N}, 9.29$. Found: C, 53.52; H, 4.35; N, 8.99.

2-(2-((3aR,4S,6S,6aS)-6-((1-(4-Chlorophenyl)-1H1,2,3-triazol-4-yl)methoxy)-2,2-dimethyltetrahydrofuro[3,4- $d][1,3]$ dioxol-4-yl)-3-(4-hydroxyphenyl)-4-oxothiazolidin-5-yl)acetic acid (7g). mp $256-258{ }^{\circ} \mathrm{C}$; IR $(\mathrm{KBr}) \vee 3532,3430,3226,2973,2830,1710,1616,1534$, $1506,1411,1258,854 \mathrm{~cm}^{-1} ;{ }^{1} \mathrm{H}$ NMR $\left(300 \mathrm{MHz}, \mathrm{CDCl}_{3}\right)$ : $\delta 11.39\left(\mathrm{~s}, 1 \mathrm{H}, \mathrm{CO}_{2} \mathrm{H}\right), 8.22(\mathrm{~d}, J=8.7 \mathrm{~Hz}, 2 \mathrm{H}, \mathrm{Ar}-\mathrm{H})$, $8.06(\mathrm{~s}, 1 \mathrm{H}, \mathrm{Ar}-\mathrm{H}), 7.52(\mathrm{~d}, J=9.2 \mathrm{~Hz}, 2 \mathrm{H}, \mathrm{Ar}-\mathrm{H})$, 7.14-6.87 (m, 4H, Ar-H), 6.14 (s, 1H, CHS), 5.76 (d, $J=$ $\left.3.6 \mathrm{~Hz}, 1 \mathrm{H}, \mathrm{C}_{1} \mathrm{H}\right), 5.42(\mathrm{~s}, 1 \mathrm{H}, \mathrm{OH}), 4.96(\mathrm{~d}, J=5.2 \mathrm{~Hz}$, $1 \mathrm{H}, \mathrm{CH}), 4.51\left(\mathrm{t}, J=3.9 \mathrm{~Hz}, 1 \mathrm{H}, \mathrm{C}_{2} \mathrm{H}\right), 4.54(\mathrm{~s}, 2 \mathrm{H}$, $\left.\mathrm{OCH}_{2}\right), 3.93-3.96\left(\mathrm{~m}, 1 \mathrm{H}, \mathrm{C}_{4} \mathrm{H}\right), 3.26(\mathrm{dd}, J=9.1,4.2 \mathrm{~Hz}$, $\left.1 \mathrm{H}, \mathrm{C}_{3} \mathrm{H}\right), 2.34\left(\mathrm{~d}, 2 \mathrm{H}, \mathrm{CH}_{2}\right), 1.53\left(\mathrm{~s}, 3 \mathrm{H}, \mathrm{CH}_{3}\right), 1.38(\mathrm{~m}$, $\left.3 \mathrm{H}, \mathrm{CH}_{3}\right) ;{ }^{13} \mathrm{C}$ NMR $\left(75 \mathrm{MHz}, \mathrm{CDCl}_{3}\right): \delta 173.6,171.6$, 154.1, 143.2, 142.1, 133.6, 131.4, 129.6, 128.1, 122.6, 120.5, 115.4, 112.6, 111.8, 107.6, 106.8, 81.8, 78.6, 76.8, 65.9, 56.9, 42.1, 36.9, 34.3; MS: $m / z\left(\mathrm{M}^{+}+\mathrm{H}\right)$ 545. Anal. Calcd for $\mathrm{C}_{27} \mathrm{H}_{27} \mathrm{ClN}_{4} \mathrm{O}_{8} \mathrm{~S}$ : C, 53.78; H, 4.52; N, 9.29. Found: C, 53.42; H, 4.25; N, 8.79.

\section{Conclusion}

A series of novel triazole linked thiazolidenone derivatives $\mathbf{6 a}-\mathbf{g}$ and $\mathbf{7 a}-\mathbf{g}$ was prepared and evaluated for their anticancer activity. The screened compound $\mathbf{7 b}$ exhibited potent anticancer activity compared to standard drug at the tested concentrations.

\section{Acknowledgements}

The authors are thankful to CSIR-New Delhi for the financial support (Project funding No: 02(247)15/EMRII). Director, CSIR- IICT, Hyderabad, India, for NMR and MS spectral analysis and Principal Vaagdevi Degree and PG College for his constant encouragement to carry out research work.

\section{References}

1. (a) K. D. Hani, D. A. Leigh, Chem. Soc. Rev. 2010, 39, 1240-1251. https://doi.org/10.1039/B901974J

(b) C. O. Kappe, Van der Eycken, E. Chem. Soc. Rev. 2010, 39, 1280-1290. https://doi.org/10.1039/B901973C

(c) A. H. El-Sagheer, T. Brown, Chem. Soc. Rev. 2010, 39, 1388-1405 https://doi.org/10.1039/b901971p

(d) A. Qin, J. W. Y. Lam, B. Z. Tang, Chem. Soc. Rev. 2010, 2522-2544. https://doi.org/10.1039/b909064a

(e) M. Meldal, C. W. Tornoe, Chem. Rev. 2008, 108, 29523015. https://doi.org/10.1021/cr0783479

(f) H. Nandivada, X. Jiang, J. Lahann, Adv. Mater. 2007, 19, 2197-2208. https://doi.org/10.1002/adma.200602739

(g) Y. L. Angell, K. Burgess, Chem. Soc.Rev. 2007, 36, 1674-1689. https://doi.org/10.1039/b701444a

(h) D. Fournier, R. Hoogenboom, U. S. Schubert, Chem. Soc. Rev. 2007, 36, 1369-1380.

https://doi.org/10.1039/b700809k

(i) J. E. Moses, A. D. Moorhouse. Chem. Soc. Rev. 2007, 36, 1249-1262. https://doi.org/10.1039/B613014N

(j) J. F. Lutz, Angew. Chem. Int. Ed. 2007, 46, 1018-1125. https://doi.org/10.1002/anie.200604050

(k) A. Dondoni, Chem.-Asian J. 2007, 2, 700-708.

https://doi.org/10.1002/asia.200700015

(1) H. C. Kolb, K. B. Sharpless, Drug Discovery Today, 2003, 8, 1128- 1137 .

https://doi.org/10.1016/S1359-6446(03)02933-7

2. A. Brick, J. Muldoon, Y.-C. Lin, J. H Elder, D. S. Goodsell, A. J Olson, V. V. Fokin, K. B. Sharpless, C.-H. Wong, ChemBioChem. 2003, 4, 1246-12148.

(b) M. J. Soltis, H. J. Yeh, K. A. Cole, N. Whittaker, R. P. Wersto, E. C. Kohn, Drug Metab. Dispos. 1996, 24, 799-806.

3. (a) W.-Q. Fan, A. R. Katritzky, 1,2,3-Triazoles, In Comprehensive Heterocyclic Chemistry II. Edited by A. R. Katritzky, C. W. Rees, V. Scriven, Elsevier, Oxford. 1996, 4, 1-126, pp. 905-1006. (b) M. Whiting, J. Muldoon, Y.-C. Lin, S. M. Silverman, W. Lindstrom, A. J. Olson, H. C. Kolb, M. G. Finn, K. B. Sharpless, J. H. Elder, V. V. Fokin, Angew. Chem. Int. Ed., 2006, 45, 1435-1439.

https://doi.org/10.1002/anie.200502161

(c) Y. Bourne, H. C. Kolb, Z. Radić, K. B. Sharpless, P. Taylor, P. Marchot, Proc. Natl. Acad. Sci. U. S. A. 2004, 101, 1449-1454. https://doi.org/10.1073/pnas.0308206100

(d) W. G. Lewis, G. Green, F. Z. Grynszpan, Z. Radić, P. R. Carlier, P. Taylor, M. G. Finn, K. B. Sharpless, Angew. 
Chem., Int. Ed. 2002, 41, 1053-1057.

https://doi.org/10.1002/1521-3773(20020315)41:6<1053:: AID-ANIE1053>3.0.CO;2-4

4. R. Huisgen, A. Padwa, 1,3-Dipolar Cycloaddition Chemistry, ed. Wiley, New York, 1984, 1, 1-176.

5. (a) N. A. Al-Maoudi, A. Y. Al-Soud, Tetrahedron Lett. 2002, 43, 4021-4022.

https://doi.org/10.1016/S0040-4039(02)00733-5

(b) B. H. M. Kuijpers, S. Groothuys, A. B. R. Keereweer, P. J. L. M. Quaedflieg, R. H. Blaauw, F. L.van Delft, F. P. J. T. Rutjes, Org. Lett. 2004, 6, 3123-3126.

https://doi.org/10.1021/o1048841o

(c) C. Srinivas, X. Fang, Q. Wang, Tetrahedron Lett. 2005, 46, 2331-2334. https://doi.org/10.1016/j.tetlet.2005.01.175

(d) S. Hotha, R. I. Anegundi, A. A. Natu, Tetrahedron Lett. 2005, 46, 4585-4588.

https://doi.org/10.1016/j.tetlet.2005.05.012

(e) S. Hotha, S. Kashyap, J. Org. Chem. 2006, 71, 364-367. https://doi.org/10.1021/jo051731q

6. (a) A. K. Jain, A. Vaidya, A. Ravichandran, S. Kashaw, R. Agarwak, Bioorg. Med. Chem. 2012, 20, 3378-3395.

https://doi.org/10.1016/j.bmc.2012.03.069

(b) A.Verma, S. Saraf, Eur. J. Med. Chem. 2008, 43, 897905. https://doi.org/10.1016/j.ejmech.2007.07.017

7. Z. Hongyu, S. Wu, S. Zhai, A. Liu, Y. Sun, R. Li, Y. Zhang, S. Ekins, P. W. Swaan, B. Fang, B. Zhang, B. Yan, J. Med. Chem. 2008, 51, 1242-1251.

https://doi.org/10.1021/jm7012024

8. (a) M. L. Barreca, J. Balzarini, A. Chimmiri, E. Declerq, L. De Luca, H. D. Holtje, M. Holte, A. M. Monforte, P. Monforte, C. Pannecouque, A. Rao, M. Zappala, J. Med. Chem. 2002, 45, 5410-5413. https://doi.org/10.1021/jm020977+

(b) A. Rao, J. Balzarini, A. Carbone, A. Chimmiri, E. Declerq, A. M. Monforte, P. Monforte, C. Pannecouque, M. Zappala, Antiviral Res. 2004, 63, 79-84.

https://doi.org/10.1016/j.antiviral.2004.03.004

(c) R. K. Rawal, R. Tripati, S. B. Katti, C. Pannecouque, E. Declerq, Bio. Org. Med. Chem. 2007, 15, 3134-3142. https://doi.org/10.1016/j.bmc.2007.02.044

9. G. C. Kuckguzel, J. R. Shchulle, A. Kaocapte, E. Declerq, F. Sahniv, M. Gulluce, Eur. J. Med. Chem. 2006, 41, 353-359. https://doi.org/10.1016/j.ejmech.2005.11.005

10. M. V. Diurano, O. Mazzoni, P. E. Calignano, F. Giorodano, A. Bolognase, J. Med. Chem. 1992, 35, 2910-2912. https://doi.org/10.1021/jm00093a025

11. (a) T. Archana, V. K. Srivastava, K. Kumar, Eur. J. Med. Chem. 2002, 37, 873-882.

https://doi.org/10.1016/S0223-5234(02)01389-2

(b) C. Dwivedi, S. S. Gupta, S. S. Parmer, J. Med. Chem. 1972, 15, 553-554. https://doi.org/10.1021/jm00275a031

12. K. G. Desai, K. R. Desai, J. Sulfur. Chem. 2006, 27, 315328. https://doi.org/10.1080/17415990600786409

13. C. M. Jackson, B. Blass, K. Coburn, L. Dijandjighian, G. Fadayel, A. Fluxe, S. J. Hodson, J. M. Janusz, M. Murawsky, J. M. Ridgeway, R. E. White, S. Wu, Bio. Org. Med. Chem.
Lett. 2007, 17, 282-284.

https://doi.org/10.1016/j.bmcl.2006.07.007

14. (a) V. R. Solomon, C. Hu, H. Lee, Bio. Org. Med. Chem. Lett. 2009, 17, 7585-7592.

https://doi.org/10.1016/j.bmc.2009.08.068

(b) B. Muenier, Acc. Chem. Res. 2008, 41, 69-77.

https://doi.org/10.1021/ar7000843

15. (a) D. Havrlyuk, L. Mosula, B. Zimenkovsy, A. Vasyleno, A. Gzella, R. Lesyk, Eur. J. Med. Chem. 2010, 5, 5012-5021. https://doi.org/10.1016/j.ejmech.2010.08.008

(b) R. Lesyk, O. Vladgimiska, S. Holota, L. Zaprutko, A. Gzella, Eur. J. Med. Chem. 2007, 42, 641-648. https://doi.org/10.1016/j.ejmech.2006.12.006

(c) D. Havrlyuk, N. Kovach, B. Zimmenkovesy, O. Vaseylenko, R. Lesyk, Arch. Pharm. Chem. Life Sci. 2011, 344, 514-522. https://doi.org/10.1002/ardp.201100055

(d) L. Mosula, B. Zimmenkovesy, D. Havrlyuk, A. V. Missir, I. C. Chiritha, R. Lesyk, Farmacia, 2009, 57, 321-330.

(e) D. Kaminskyy, O. Vasylenko, D. Atamanyuk, A. Gzella, R. Lesyk, Synlett. 2011, 10, 1385-1388.

16. (a) C. O. Kappe, Angew. Chem. Int.Ed. 2004, 43, 62506284. https://doi.org/10.1002/anie.200400655

(b) C. O. Kappe, D. Dallinger, Nat. Rev. Drug Discovery. 2006, 5, 51-63. https://doi.org/10.1038/nrd1926

17. Y. Kumar, V. Bahadur, A. K. Singh, V. S. Parmer, E. V. van der Eycken, B. K. Singh, Beilstein J. Org. Chem. 2014, 10, 113-118.

18. A. Srinivas, M. Sunitha, C. Govind Rao, Acta Chim. Slov. 2016, 63, 344-350. https://doi.org/10.17344/acsi.2015.2124

19. A. Srinivas, Acta Chim. Slov. 2016, 63, 173-179. https://doi.org/10.17344/acsi.2015.2124

20. A. Srinivas, M. Sunitha, G. Rajesh Kumar, Org. Commun. 2016, 9.1, 1-8.

21. A. Srinivas, M. Sunitha, Indian J. Chemistry sec B. 2016, $55 B, 102-109$.

22. A. Srinivas, A. Nagaraj, C. S. Reddy, Eur. J. Med. Chem. 2010, 45, 2353-2358. https://doi.org/10.1016/j.ejmech.2010.02.014

23. C. S. Reddy, A. Srinivas, M. Sunitha, A. Nagaraj, J. Heterocycl. Chem. 2010, 47, 1303-1309. https://doi.org/10.1002/jhet.474

24. C. S. Reddy, A. Nagaraj, A. Srinivas, G. P. Reddy, Indian J. Chem. 2010, 49B, 617-622.

25. A. Srinivas, C. S. Reddy, A. Nagaraj, Chem. Pharm. Bull. 2009, 57, 685-693. https://doi.org/10.1248/cpb.57.685

26. C. S. Reddy, A. Srinivas, A. Nagaraj, J. Heterocycl. Chem. 2009, 46, 497-502. https://doi.org/10.1002/jhet.100

27. C. S. Reddy, A. Nagaraj, A. Srinivas, G. P. Reddy, Indian J. Chem. 2009, 48B, 248-254.

28. C. S. Reddy, A. Srinivas, A. Nagaraj, J. Heterocycl. Chem. 2008, 45, 1121-1125. https://doi.org/10.1002/jhet.5570450428

29. C. S. Reddy, G. P. Reddy, A. Nagaraj, A. Srinivas, Org. Commun. 2008, 1, 84-94.

30. P. A. Levene, G. M. Meyer, J. Biol. Chem. 1931, 92, 257262. 


\section{Povzetek}

S postopkom sinteze v eni sami posodi smo s pomočjo kondenzacije (3aS,4S,6S,6aS)-6-((1-(4-klorofenil)-1H-1,2,3-triazol-4-il)metoksi)-2,2-dimetiltetrahidrofuro[3,4- $d][1,3]$ dioksol-4-karbaldehida 5 z merkapto kislinami in primarnimi amini v prisotnosti $\mathrm{ZnCl}_{2}$ pripravili serijo novih hibridnih heterociklov $\mathbf{6 a}-\mathbf{g}$ in $\mathbf{7 a}-\mathbf{g}$. Sinteze so bile izvedene tako pod mikrovalovnimi kot tudi konvencionalnimi pogoji segrevanja. Spojino 5 smo pripravili iz di-aceton D-manoze s pomočjo »click « reakcije, s sledečo odstranitvijo primarne acetonidne zaščite in z oksidativnim razcepom. Karakterizacijo novih spojin smo izvedli s pomočjo IR, NMR, MS in elementne analize. Za nove spojine smo določili tudi delovanje proti različnim rakastim celicam. 